\title{
Petrografia e química mineral do Granito São Geraldo: evidências de magmatismo peraluminoso na região de Porto Alegre, RS
}

Daniel Triboli VIEIRA', Rodrigo Chaves RAMOS', Edinei KOESTER², Maria Lidia VIGNOLLELARGE ${ }^{3}$, Carla Cristine PORCHER² ${ }^{2}$ Clovis GONZATI ${ }^{3}$, Márcia Elisa BOSCATO GOMES ${ }^{3}$, Laércio DAL OLMO-BARBOSA ${ }^{1}$, Ana Karina SCOMAZZON \& Taís FONTES PINTO’

1 Programa de Pós-Graduação em Geociências, Instituto de Geociências, Universidade Federal do Rio Grande do Sul. Caixa Postal 15.001, CEP 91501-970, Porto Alegre, RS, Brasil (danieltriboli@hotmail.com, rodrigo.chaves@ufrgs.br,dal.barbosa@ufrgs.br, tais.fontes1@gmail.com).

2 Departamento de Geologia, Instituto de Geociências, Universidade Federal do Rio Grande do Sul. (koester@ufrgs.br, carla.porcher@ufrgs.br).

3 Departamento de Mineralogia e Petrologia, Instituto de Geociências, Universidade Federal do Rio Grande doSul. (lidia.vignol@ufrgs.br, gonzatti@ufrgs.br, marcia.boscato@ufrgs.br).

${ }^{4}$ Departamento de Paleontologia e Estratigrafia de Geociências, Universidade Federal do Rio Grande do sul (akscomazzon@ufrgs.br)

Resumo. Este trabalho descreve a primeira ocorrência de um granito peraluminoso na região de Porto Alegre, denominado Granito São Geraldo. Neste estudo foram realizadas análises petrográficas (microscopia óptica e eletrônica) e de química mineral (microssonda eletrônica) em lâminas delgadas oriundas de testemunhos de sondagem. O granito apresenta textura equigranular hipidiomórfica fina a média e composição que varia de sieno a monzogranítica. Sua mineralogia é constituída por K-feldspato (37-48\%), quartzo (17-33 \%), plagioclásio (23-28 $\%$ ), muscovita + biotita (em média 14\%) e, subordinadamente (< $1 \%$ ), granada, zircão, monazita, apatita, ilmenita e magnetita. A biotita, de origem primária, apresenta teores de elementos maiores (e.g. Al, Fe e Mg) compatível com as de granitos peraluminosos. A muscovita em geral é magmática, com composição similar a dos granitos fortemente peraluminosos (e.g. teores de $\mathrm{Al}, \mathrm{Fe}, \mathrm{Mg}$ e Ti). Os teores de Or do K-feldspato (ortoclásio) variam entre 86-97 \%. O plagioclásio é predominante o oligoclásico, subordinadamente apresentando composição albítica. Teores elevados de espessartina da granada (26-32 \%) sugerem uma origem magmática. A apatita (fluorapatita) apresenta teores de $\mathrm{F}$ entre 3,0-4,5\%. 0 caráter peraluminoso deste granito o difere de todos os granitos descritos na região de Porto Alegre. Sua composição é similar a dos granitos com duas micas que compõem a Suíte Cordilheira (Batólito Pelotas), a qual engloba a maioria dos granitos peraluminosos tipo-S, sintranscorrentes a zonas de cisalhamento transcorrentes dúcteis encontradas no domínio oriental do Cinturão Dom Feliciano.

Palavras-chave. Petrografia, Granito São Geraldo, Granito Peraluminoso, Suíte Cordilheira.

\begin{abstract}
Petrography and mineral Chemistry of the São Geraldo Granite: eVIDENCE of PeRALUMinous MAgmatism IN THE Porto Alegre REgION. The present work describes the first occurrence of a peraluminous leucogranite in the Porto Alegre city region, named São Geraldo Granite. Thin sections from drill cores were studied through petrography (optical and electron microscopy) and mineral chemistry (electron probe microanalysis). The granite shows a medium to fine grained, equigranular hypidiomorphic texture, and a composition ranging from sieno- to monzogranitic. Its mineralogy comprises K-feldspar (37-48 \%), quartz (17-33\%), plagioclase (23-28\%), muscovite + biotite (7 to $11 \%$ ), and subordinate amounts (< $1 \%$ ) of garnet, zircon, monazite, apatite, ilmenite, and magnetite. The biotite, interpreted as magmatic in origin, shows major element concentrations (e.g. Al, $\mathrm{Fe}$, and $\mathrm{Mg}$ ) compatible with those generated in peraluminous granites. The muscovite is predominantly magmatic, with a composition compatible with those of the strongly peraluminous granites. The Or contents of the K-feldspar (orthoclase) range from 86 to $97 \%$. The plagioclase is mostly oligoclase, showing secondary albitic composition. The spessartine contents of the garnet (26-32 \%) suggest a magmatic origin. The apatite (fluorapatite) shows F concentration between $3.0-4.5 \%$. The peraluminous character of the studied granite differs from all granites described in the Porto Alegre region. Its composition is similar to those of the Cordilheira Suite (Pelotas Batholith), which encompasses most of the peraluminous S-type granites syncinematic emplaced in ductile shear zones found in the eastern domain of the Dom Feliciano Belt.
\end{abstract}

Keywords. Petrography; São Geraldo Granite; Peraluminous Granite; Cordilheira Suite 


\section{Introdução}

Granitos com biotita e muscovita são geralmenteassociados ao magmatismo granítico peraluminoso. Este tipo de magmatismo pode ser formado por fusão crustal em porções profundas de cinturões colisionais (White \& Chappell, 1974; Patiño-Douce \& Johnston, 1991; Barbarin, 1996; Patiño-Douce \& McCarty, 1998; Gill, 2010; Pérez-Soba \& Villaseca, 2010), podendo estar relacionado com a descompressão adiabática associada com o período pós-colisional (Liégeois et al., 1998; Barbarin, 1999; Reichardt et al., 2010; Sawyer et al., 2011; Brown, 2013), ou ainda, ao fracionamento de magmas básicos ou intermediários (Wilson, 1989; Sawyer et al., 2011; Brown, 2013).

Na região de Porto Alegre (RS) ocorrem diversas exposições de granitoides com idades entre 630-600 Ma (relacionados aos estágios finais do ciclo orogênico Brasiliano/Panafricano), além de gnaisses que representam crosta continental mais antiga, com idades de cristalização em torno de 800 Ma (Koester et al., 2001a, 2016). Estas unidades situam-se na porção nordeste do Batólito Pelotas (FragosoCésar et al., 1986), que integra em partes o domínio oriental do Cinturão Dom Feliciano no Escudo Sul-rio-grandense. Os granitos da região apresentam formas alongadas segundo a direção NE-SW e concordantes com as principais estruturas regionais, sugerindo posicionamento controlado pela tectônica brasiliana (Fernandes et al., 1992; Bitencourt \& Nardi, 2000; Oliveira et al., 2001; Philipp et al., 2002; Philipp \& Machado, 2005; Koester et al., 2016).

Recentemente foram encontrados em testemunhos de sondagem granitos com duas micas, ocorrência inédita nesta região. Estes testemunhos foram obtidos junto às obras de planejamento da linha 2 do metrô da cidade de Porto Alegre, que se estenderá desde o bairro Centro Histórico em direção ao leste, para os bairros Floresta, São Geraldo, Navegantes, Humaitá e Anchieta. O presente estudo tem como objetivo a caracterização petrográfica dessa nova ocorrência de granito com duas micas, defınido neste trabalho como Granito São Geraldo, e possíveis correlações com outros granitoides peraluminosos que ocorrem no Batólito Pelotas. Para este fim foram empregadas técnicas de petrografia com ênfase na caracterização mineral, textural e microestrutural utilizando-se microscopia óptica e microscopia eletrônica de varredura (MEV), bem como análises de química mineral (WDS) em microssonda eletrônica.

\section{2 Área de estudo, materiais e métodos}

\section{1 Localização da área}

A área de estudo está inserida no contexto geológico do Cinturão Dom Feliciano, cinturão orogênico neoproterozoico relacionado ao ciclo Brasiliano/Pan-Africano. Esse cinturão se estende de Punta del Este (Uruguai) até o leste do estado de Santa Catarina no Brasil (e.g. Heilbron et al., 2004). No Rio Grande do Sul, o Cinturão Dom Feliciano é dividido em três domínios principais, baseado em critérios geológicos e geofísicos (Fernandes et al., 1995a, 1995b; Costa, 1997): domínios Ocidental, Central e Oriental. 0 Domínio Oriental, onde está situado o granito alvo deste estudo, é limitado a oeste pela Zona de Cisalhamento Dorsal do Canguçu e Sutura de Porto Alegre, que o separam do Domínio Central; a leste, pela Planície Costeira (sedimentos quaternários); e a norte, por rochas sedimentares paleozoicas e mesozoicas da Bacia do Paraná. Para sul esse domínio se estende até Punta del Este, no Uruguai (Fig. 1).

No Rio Grande do Sul o Domínio Oriental do Cinturão Dom Feliciano equivale parcialmente ao Batólito Pelotas (Fragoso-César et al., 1986), onde predominam granitoides cálcio-alcalinos alto-K de idades neoproterozoicas, vinculados à zona de subducção (e.g. Philipp, 1990; Philipp et al., 2016). Subordinadamente são encontrados xenólitos métricos a quilométricos de rochas metamórficas diversas, que representam crosta continental e oceânica antiga (e.g. Fragoso-César et al., 1986; Philipp et al., 2002; Gregory et al., 2015; Koester et al., 2016; Martil et al., 2017). No Batólito Pelotas foram caracterizadas seis suítes graníticas denominadas de Pinheiro Machado, Erval, Viamão, Encruzilhada do Sul, Cordilheira e Dom Feliciano, e uma sienítica, a Suíte Piquiri (e.g. Fragoso-César et al., 1986; Figueiredo et al., 


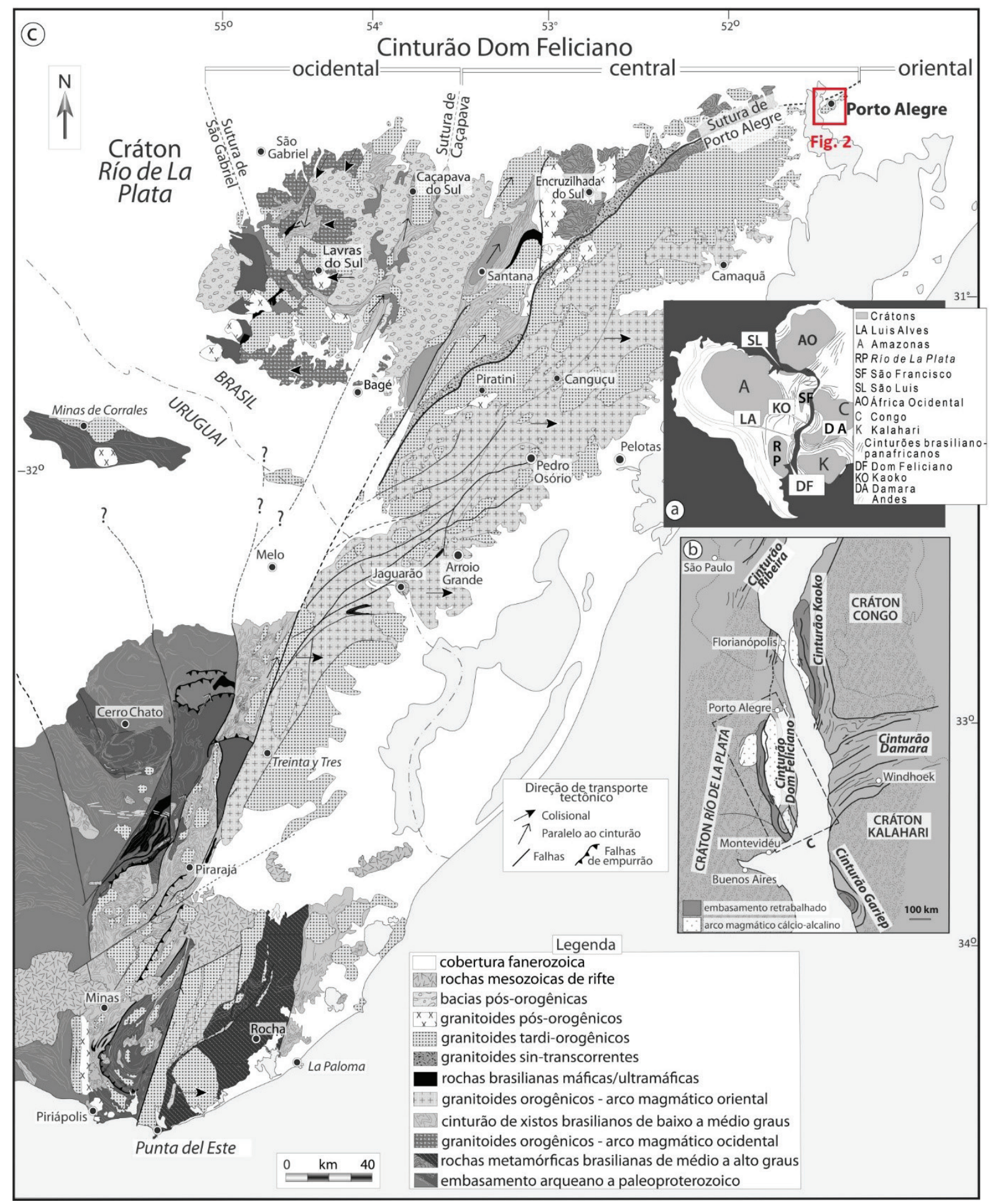

Figura 1. Esboço geológico do Cinturão Dom Feliciano no Escudo Uruguaio-sul-rio-grandense (modificado de Masquelin et al., 2012). A) Configuração do supercontinente Gondwana com as principais áreas cratônicas; B) Localização do Cinturão Dom Feliciano e cinturões africanos adjacentes na configuração do supercontinente Gondwana; C) Mapa geológico do Cinturão Dom Feliciano e Cráton Rio de la Plata no sul do Brasil e Uruguai.

Figure 1. Geological context of the Dom Feliciano Belt in the Uruguayan-sul-rio-grandense Shield (modified from Masquelin et al., 2012). A) Gondwana supercontinent configuration with main cratonic areas; B) Location of the Dom Feliciano Belt and adjacent African Belts on Gondwana supercontinent configuration; C) Geologic map of the Dom Feliciano Belt and Rio de la Plata Craton in South Brazil and Uruguay. 
1990; Philipp, 1998; Philipp \& Machado, 2001; Philipp et al., 2002).

A Suíte Pinheiro Machado é constituída por granitoides com assinatura química cálcioalcalina, médio a alto- $K$, metaluminosa a fracamente peraluminosa. Os granitoides da Suíte Viamão possuem assinatura geoquímica cálcio-alcalina alto-K e variam de metaluminosos a fracamente peraluminosos, enquanto a Suíte Cordilheira apresenta granitos de caráter exclusivamente peraluminoso (Philipp, 1998; Philipp et al., 2002, 2013). Os sienitos da Suíte Piquiri têm afinidade shoshonítica, enquanto os granitos da Suíte Encruzilhada do Sul são alcalinos e metaluminosos (Nardi et al., 2007, 2008; Plá Cid et al., 2003, 2005). Na sua maioria, os corpos graníticos da Suíte Dom Feliciano são cálcio-alcalinos alto-K, com elevado grau de diferenciação (75-78 \% $\mathrm{SiO}_{2}$ ) (Philipp, 1998; Philipp \& Machado, 2001; Philipp et al., 2002).

Na região de Porto Alegre (Fig. 2), as rochas mais antigas são denominadas como Gnaisses Ponta Grossa, de origem paraderivada, ocorrendo na forma de xenólitos nos Gnaisses Chácara das Pedras (Oliveira et al., 2001). Os Gnaisses Chácara das Pedras, de origem ortoderivada e idade de cristalização de 777,3 \pm 3,6 Ma (U-Pb SHRIMP em zircão: Koester et al., 2016), ocorrem como xenólitos no Granodiorito Três Figueiras. Essas três unidades constituem o embasamento dessa região.

Este embasamento é intrudido pelo Granodiorito Lomba do Sabão, sintranscorrente à Zona de Cisalhamento de Porto Alegre, e pelo Granito Santana, o qual aproveita a descontinuidade física da Sutura de Porto Alegre (Fig. 2). Posteriormente essas rochas foram intrudidas pelos granitos pós-tectônicos à transcorrência (Menegat et al., 1998; Oliveira et al., 2001; Koester et al., 2001a). Os granitos pós-tectônicos foram agrupados por Oliveira et al. (2001) em três suítes graníticas: Viamão (constituída pelos granitos Saint Hilaire e Pitinga), Porto Alegre (constituída pelos granitos Independência, São Caetano, Feijó, Lami, São Pedro e Restinga) e Itapuã (constituída pelos granitos Santana, Cantagalo, Santo Antônio e Passo das Pedras).

Philipp (1998) e Oliveira et al. (2001) caracterizaram a geoquímica dessas suítes. A Suíte Intrusiva Viamão apresenta assinatura cálcio-alcalina alto-K, enquanto a Suíte Intrusiva Porto Alegre apresenta assinaturas cálcioalcalinas mais evoluídas em relação a Suíte Viamão. A Suíte Intrusiva Itapuã é compatível com os granitos metaluminosos da associação alcalina descrita por Nardi \& Bonin (1991).

\subsection{Materiais e métodos}

Para este trabalho, foram utilizadas amostras coletadas de 9 testemunhos de sondagem, distribuídos conforme a figura 2 . Foram selecionadas 13 amostras do Granito São Geraldo que ocorrem em profundidades de 4,5 a 21,5 m para confecção de lâminas delgadas junto ao Núcleo de Preparação de Amostras do Centro de Estudos em Petrologia e Geoquímica (CPGq), Instituto de Geociências da Universidade Federal do Rio Grande do Sul. As descrições das lâminas foram realizadas com auxílio de microscópio óptico Meiji Techno ML9720.

Duas lâminas delgadas (SM9 e SM43) foram selecionadas para análises de química mineral em microssonda eletrônica. As lâminas foram devidamente polidas e metalizadas com carbono por evaporação. As análises foram realizadas com auxílio de um Cameca SXFive equipado com cinco espectrômetros WDS (Wavelength Dispersive Spectrometry), no Laboratório de Microssonda Eletrônica, CPGq, Instituto de Geociências da mesma Universidade. Para a análise de elementos maiores nos silicatos e óxidos, as condições analíticas consistiram em voltagem de aceleração de $15 \mathrm{kV}$, corrente de 10 nA, e diâmetro do feixe eletrônico da ordem de 5 $\mu \mathrm{m}$.

Para as análises quantitativas de microssonda eletrônica foram usados os seguintes padrões: albita para $\mathrm{Na}(8,6 \% \mathrm{Na}$; 10,34\% Al; 32,03\% Si; 48,76\% 0; 0,18\% K; 0,09\% Ca), wollastonita para Si e Ca $(33,9337 \%$ Ca; 23,8201\% Si; 41,17\% 0; 0,0074\% Na; 0,006\% Mg; 0,006\% Ti; 0,4879\% Mn; 0,171\% Fe), diopsídio para Mg (11,23\% Mg; 18,39\% Ca; 25,88\% Si; 44,3\% O; 0,05\% Al; 0,05\% Ti; 0,04\% Mn; 0,04\% Fe), sanidina para Al e K (46,28\% 0; 9,93\% Al; 30,23\% Si; 10,05\% $\mathrm{K} ; 0,14 \% \mathrm{Fe} ; 0,98 \% \mathrm{Ba} ; 2,23 \% \mathrm{Na})$, óxido de cromo 


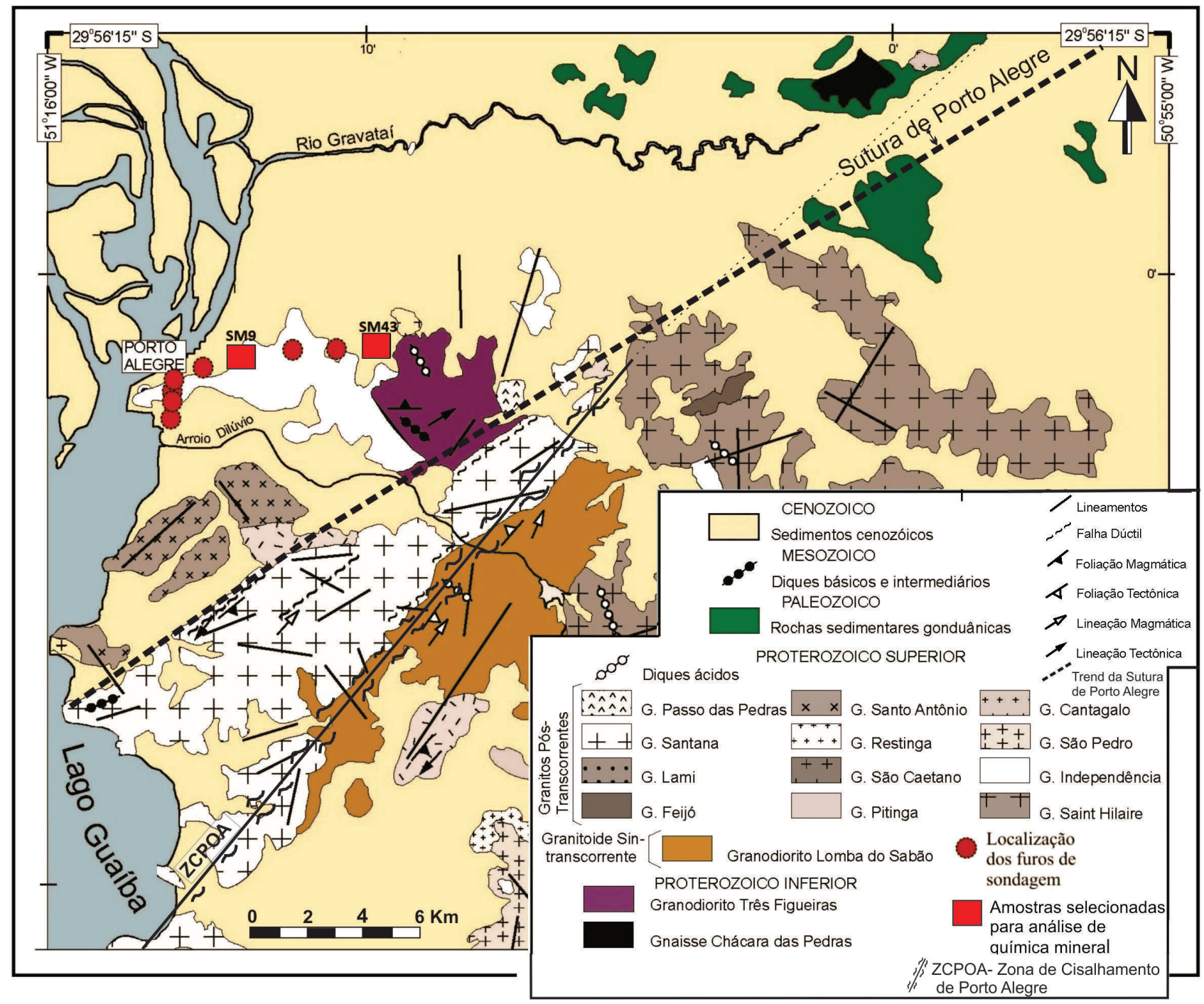

Figura 2. Mapa geológico da região de Porto Alegre com a localização dos furos de sondagem amostrados (modificado de Oliveira et al., 2001).

Figure 2. Geologic map of the Porto Alegre region with the location of the sampled drill holes (modified from Oliveira et al., 2001).

para Cr $(68,4195 \%$ Cr; $31,5805 \%$ O), rodonita para Mn (32,8499\% Mn; 22,1126\% Si; 37,7621\% O; 1,1216\% Mg; 5,0993\% Ca; 0,7905\% Fe), hematita para Fe $(69,9426 \% \mathrm{Fe} ; 30,0574 \%$ O) e rutilo para Ti (59,95\% Ti; 40,05\% 0).

\section{Resultados}

\subsection{Características geológicas e petrográficas do Granito São Geraldo}

Neste trabalho, o granito estudado é formalmente denominado de Granito São Geraldo. Essa denominação faz referência a um dos bairros onde foram realizados os furos de sondagem para as obras do metrô anteriormente mencionadas. A partir da descrição dos testemunhos verificou-se a ocorrência de um granito com duas micas com cores que variam de laranja (quando alterado) a cinza, até então nunca descrito para a região de Porto Alegre. A correlação dos furos de sondagem mostra que o Granito São Geraldo possui uma extensão mínima de $10 \mathrm{~km}$.

O granito possui textura predominante equigranular hipidiomórfica média a fina (Fig. 3), e apresenta por vezes uma trama tectônica protomilonítica. Sua mineralogia essencial é composta por K-feldspato, plagioclásio, quartzo, muscovita e/ou biotita. Minerais acessórios como granada, monazita, apatita e zircão são comuns. 

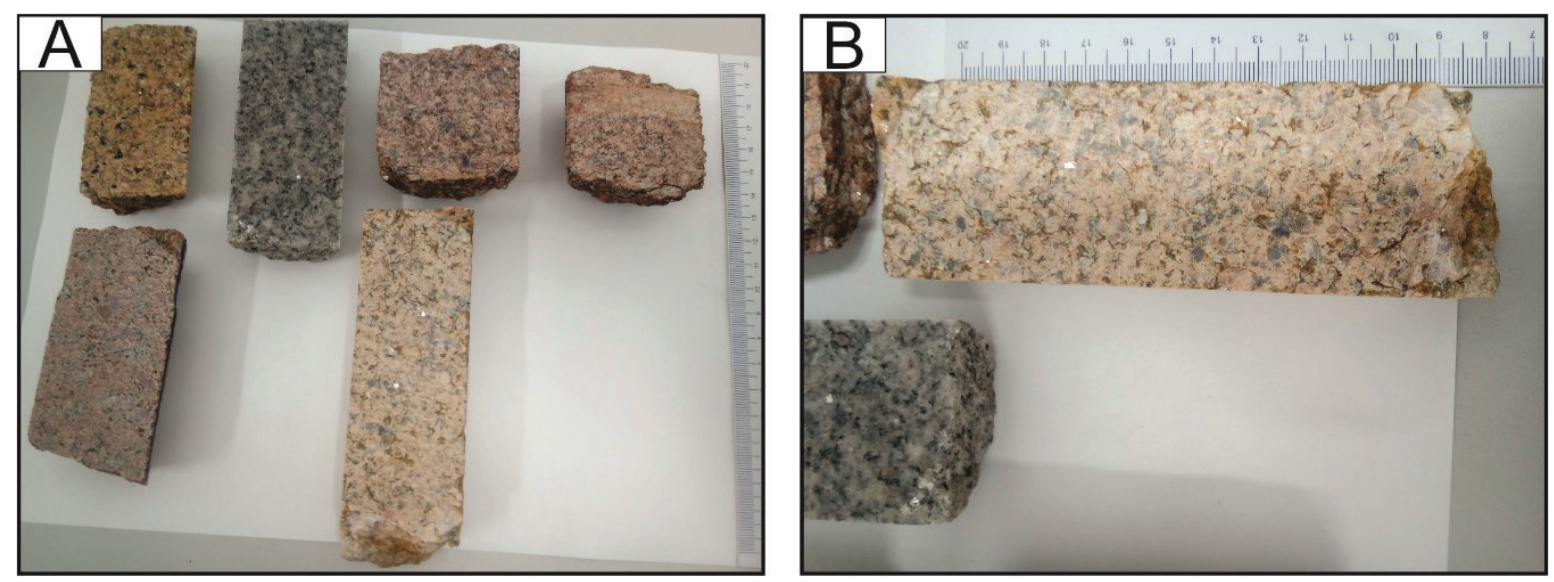

Figura 3. Testemunhos de sondagens do Granito São Geraldo. A) Variação de cores dos testemunhos estudados; B) Detalhe do granito, mostrando a textura equigranular média.

Figure 3. Drill cores from the São Geraldo Granite. A) Color variations of the studied drill cores; B) Detail of the granite, showing the equigranular medium-grained texture.

Outra característica apresentada pelo Granito São Geraldo é a presença de xenólitos de gnaisses (Fig. 4). Esses xenólitos são descritos por Gomes (2016) e correlacionados com os Gnaisses Chácara das Pedras (Philipp \& Campos, 2004; Koester et al., 2016).

Ao microscópio foi possível estimar as proporções modais de quartzo, K-feldspato e plagioclásio utilizando o método de contagem de pontos (aproximadamente 450 pontos por lâmina). As proporções modais foram recalculadas para $100 \%$ e projetadas no diagrama QAPF (Fig. 5) de Streckeisen (1976). O Granito São Geraldo apresenta composições que variam de monzo a sienograníticas, similares a associação leucocrática peraluminosa proposta por Nardi (2016), modificada de Lameyre \& Bowden (1982).

A mineralogia principal é composta por K-feldspato (37-48 \%), quartzo (17-33\%), plagioclásio (23-28 \%), muscovita (5-9 \%) e biotita (4-10\%). Os minerais acessórios (1\%) são granada, zircão, monazita, apatita e opacos (ilmenita e magnetita).

O K-feldspato ocorre comumente na forma de cristais prismáticos subédricos alongados de tamanhos que variam de 0,5 a $3 \mathrm{~mm}$ de comprimento. Localmente são observadas texturas poiquilíticas em cristais maiores, caracterizadas por diversas inclusões euédricas a anédricas de biotita, plagioclásio, muscovita e quartzo (Fig. 6A). Em geral, esses cristais apresentam um padrão principal de geminação segundo a lei de Carlsbad e um padrão secundário de geminação do tipo xadrez que se desenvolve principalmente nas bordas dos grãos, sugerindo inversão incompleta ortoclásio-microclinio.

Agregados mirmequíticos ocorrem localmente no contato com plagioclásio, sendo em geral bem desenvolvidos, predominando os tipos marginais descritos por Phillips (1980), nas suas variedades bulbosa e planar. A ocorrência de lobos de mirmequitos independentes na matriz possivelmente se deve à deformação progressiva dos cristais de feldspato que ocasiona recristalização nos limites dos grãos, propiciando a individualização dos lobos mirmequíticos. Extinção ondulante e formação de subgrãos com rotação progressiva para grãos recristalizados são pouco comuns, estando ambas as características restritas aos termos protomiloníticos.

O plagioclásio é caracterizado por cristais tabulares subédricos, em geral com dimensões que variam de 0,3 a 3,5 mm de comprimento. Ocorrem com frequência zonação normal e maclas polissintéticas (Fig. 6B). A textura poiquilítica também é observada nos cristais de plagioclásio, sendo caracterizada em geral por inclusões de muscovita. Nos termos protomiloníticos é comum a presença de cristais com extinção ondulante e a formação de maclas em cunhas e curvadas (kink bands) (Fig. 6C).

O quartzo possui extinção ondulante e tende a formar agregados de cristais com formas irregulares e alongadas, de tamanho entre 0,3 e 2,2 mm. A recristalização por bulging é comum, 


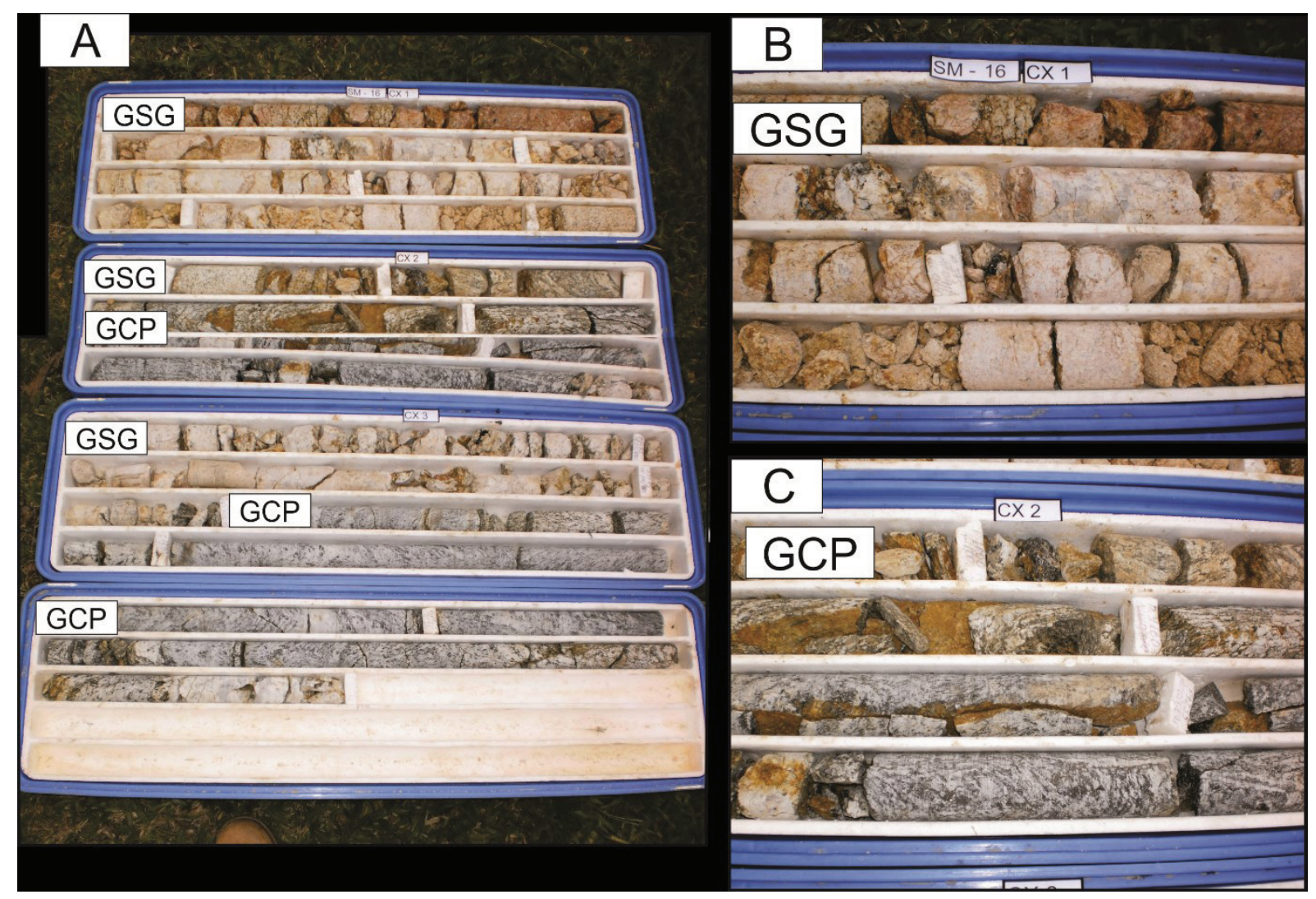

Figura 4. Testemunhos de sondagens. A) Testemunhos de sondagem do Granito São Geraldo (GSG) mostrando a presença de xenólitos dos Gnaisses Chácara das Pedras (GCP); B) Detalhe do Granito São Geraldo; C) Detalhe dos Gnaisses Chácara das Pedras.

Figure 4. Drill cores. A) Drill cores of the São Geraldo Granite (GSG) showing the xenoliths of the Chácara das Pedras Gneisses (GCP); B) Detail of the São Geraldo Granite; C) Detail of the Chácara das Pedras Gneisses.

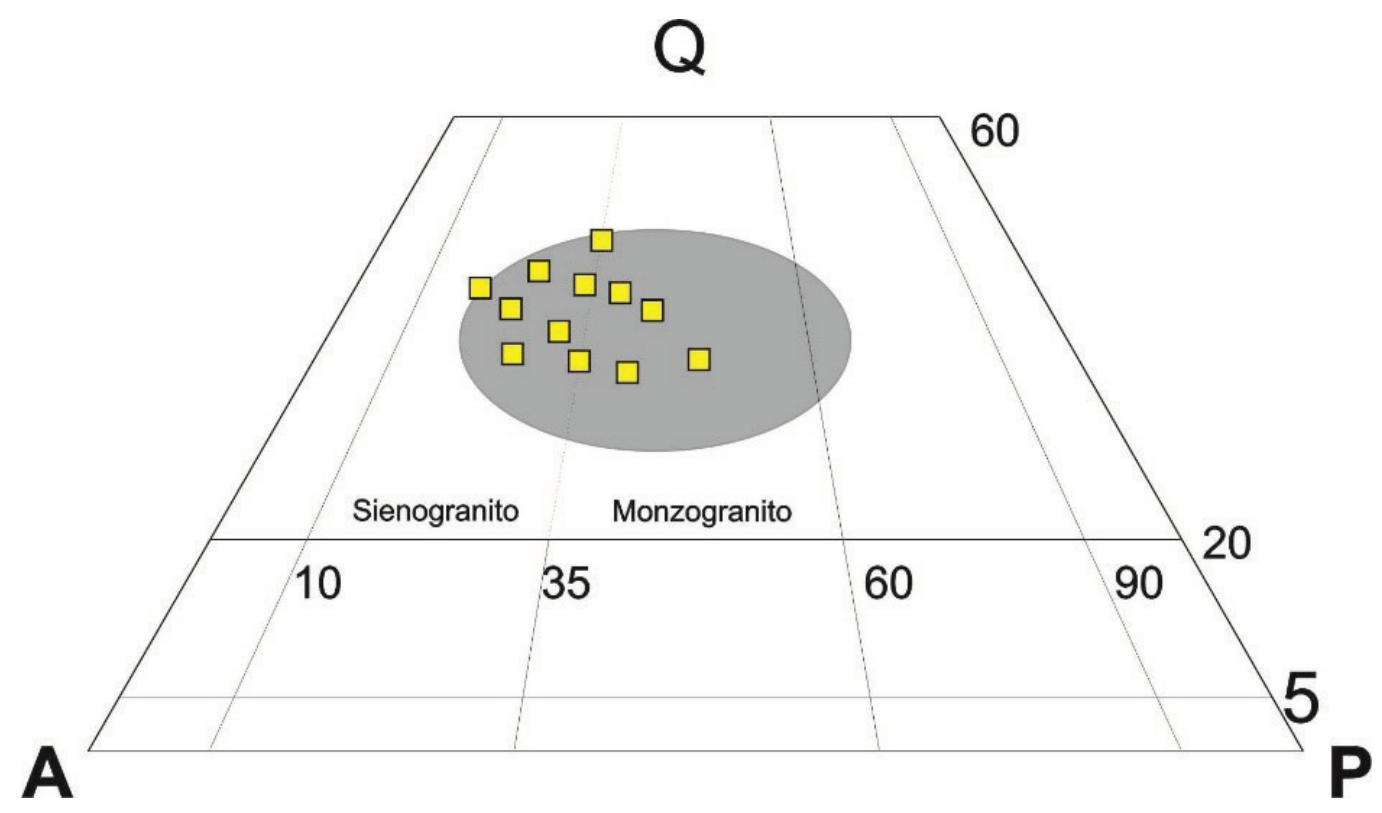

Figura 5. Composição modal do Granito São Geraldo (quadrados amarelos) projetada no diagrama $Q A P(Q=$ quartzo; $A=$ feldspato alcalino; $P$ = plagioclásio) para rochas plutônicas (Streckeisen, 1976), com o campo de distribuição da associação leucocrática peraluminosa (elipse cinza) modificado de Lameyre \& Bowden (1982).

Figure 5. Modal composition of the São Geraldo Granite (yellow squares) projected on the $Q A P(Q=q u a r t z ; A=$ alkali feldspar; $P$ = plagioclase) diagram for plutonic rocks (Streckeisen, 1976), with the peraluminous leucocratic association field (gray ellipse) modified from Lameyre \& Bowden (1982). 
o que faz com que os contatos dos grãos fiquem crenulados e interpenetrados, formando por vezes agregados policristalinos alongados e lenticulares que circundam os cristais de feldspato. Localmente é observado nos termos protomiloníticos feições como recristalização por migração de limite de grão formando texturas granoblásticas poligonais (contatos em pontos tríplices) e agregados policristalinos com extinção do tipo tabuleiro xadrez (Fig. 6D).

A muscovita e a biotita ocorrem em proporções variáveis, ora predominando a primeira, ora a última (Fig. 7A). Ambas são, em geral, bem formadas com tamanhos que variam de 0,1 a $4 \mathrm{~mm}$ (Fig. 6E). Por vezes nesses minerais ocorrem inclusões de zircão, monazita e apatita. Dois tipos de muscovita são observados: as primárias que ocorrem como lamelas subédricas que variam entre 0,2 a 0,8 $\mathrm{mm}$ e/ou cristais euédricos mais desenvolvidos, com dimensões entre 3 e $4 \mathrm{~mm}$ de comprimento, subordinadamente, as secundárias que se desenvolvem sobre os planos de clivagem ou nas bordas das biotitas. A biotita ocorre na forma de lamelas, entre 0,1 até $1,7 \mathrm{~mm}$ de comprimento com pleocroísmo variando em tons de marrom amarelado até castanho escuro (Fig. 6F). Feições de deformação nas micas são comuns, como extinção ondulante e formação de mica-fish e microdobramentos em kink bands.

O principal mineral acessório é a granada que ocorre na forma de cristais subédricos (Fig. 6F) com diâmetros que variam de $0,05 \mathrm{~mm}$ a $1,2 \mathrm{~mm}$, por vezes apresentando inclusões de quartzo (Fig. 7B). Outros minerais acessórios observados são a monazita, apatita e zircão. Em geral, esses minerais estão inclusos nas micas, desenvolvendo halos pleocroicos devido à metamictização do zircão e da monazita (Fig. 6G). Os cristais de apatita em geral são euédricos, com hábito prismático longo, fazendo contatos retos com os demais minerais. Geralmente ocorrem como inclusões em feldspatos e micas, sugerindo cristalização em estágio magmático precoce, também ocorrendo em contato com cristais de monazita, conforme observado na figura 7C. Dentre os minerais opacos ocorrem ilmenita e magnetita.

\subsection{Química mineral}

Foram realizadas análises pontuais para a caracterização química dos minerais essenciais e acessórios de 2 amostras do granito estudado. Os resultados analíticos obtidos foram comparados com os dados mostrados por Koester et al. (2001b) para os granitos peraluminosos que ocorrem na região de Encruzilhada do Sul, RS.

As análises de biotita (Tab. 1) quando plotadas no diagrama ternário de Nachit et al. (1985) indicam um caráter primário para as mesmas (Fig. 8A). No diagrama de classificação $\mathrm{Fe} \mathrm{/} \mathrm{(FeO+MnO)} \mathrm{versus} \mathrm{Side} \mathrm{Deer} \mathrm{etal.} \mathrm{(1992)} \mathrm{(Fig.}$ 8B), as biotitas se distribuem no campo superior (biotitas sensu stricto). Quando plotadas nos diagramas de Abdel-Rahman (1994) (Fig. 9), as biotitas do Granito São Geraldo se distribuem no campo das rochas de composição peraluminosa $(P)$.

As análises químicas realizadas nas muscovitas (Tab. 2) evidenciam dois tipos quando plotadas no diagrama $\mathrm{FeO}-\mathrm{TiO}_{2}-\mathrm{MgO}$ (Fig. 10A) de Speer \& Becker (1992). No diagrama de Zane \& Rizzo (1999) (Fig. 10B), as muscovitas se distribuem no campo dos granitos fortemente peraluminosos.

Os cristais de K-feldspato são classificados como ortoclásio e mostram teores de Or entre 86 a 97 \% que decrescem do núcleo em direção à borda (Tab. 3). Os dados químicos dos cristais de plagioclásio mostram uma composição principal do tipo oligoclásio e secundária do tipo albita, conforme mostrado na tabela 3. Perfis núcleo-borda nesses cristais demonstram enriquecimento em sódio, e empobrecimento em cálcio do núcleo para a borda, o que constitui um zoneamento ígneo normal (Tab. 4).

As granadas analisadas apresentam teores de almandina entre 63 e $71 \%$, e de espessartina entre 26 e 32 \%. Suas concentrações de FeO variam de 25 a $31 \%$, e de $\mathrm{Al}_{2} \mathrm{O}_{3}$ entre 20 e $22 \%$ (Tab. 5). Os teores elevados de espessartina sugerem uma origem magmática, uma vez que granadas de origem metamórfica possuem teores inferiores a 5 \% (Searle et al., 1993).

Os cristais de apatita investigados (Tab. 6) correspondem a fluorapatitas. Essa composição sugere uma origem ígnea, uma vez que 

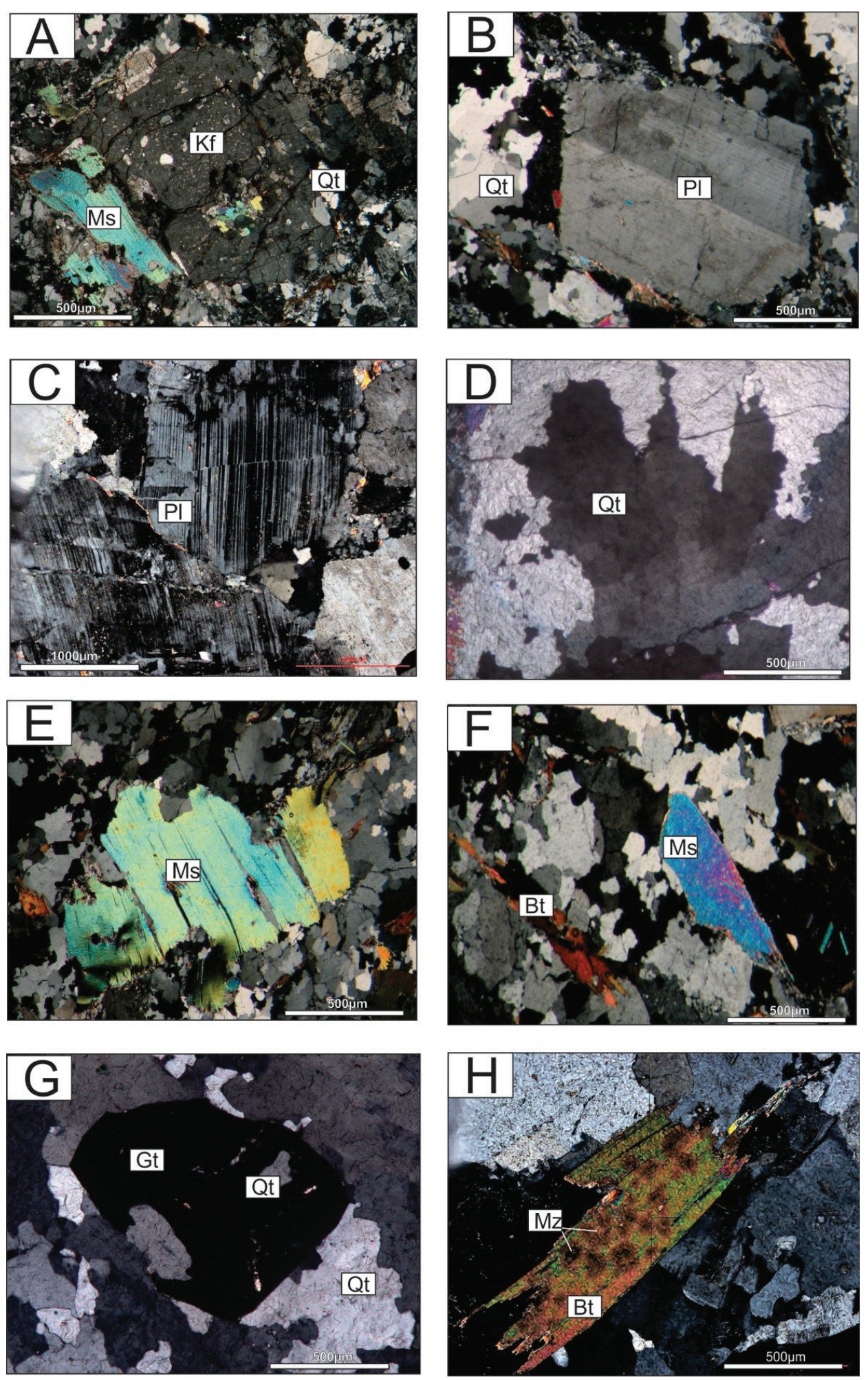

Figura 6. Fotomicrografias (nicóis cruzados) mostrando aspectos microscópicos do Granito São Geraldo. A) Cristal de $\mathrm{K}$-feldspato com inclusões de quartzo, plagioclásio e muscovita; B) Cristal de plagioclásio zonado em matriz recristalizada; C) Cristal de plagioclásio com deformação dos planos de macla; D) Quartzo com recristalização por migração de limite de grão; E) Cristal de muscovita; F) Cristais de muscovita e biotita; G) Granada com inclusões de quartzo; H) Biotita com inclusões de monazita. Abreviações: $\mathrm{Bt}=$ biotita; $\mathrm{Ms}=$ muscovita; $\mathrm{Mz}$ = monazita; $\mathrm{PI}$ = plagioclásio; $\mathrm{Qt}=\mathrm{quartzo} ; \mathrm{Kf}=$ $\mathrm{K}$-feldspato e $\mathrm{Gt}=$ granada.

Figure 6. Photomicrographs (crossed polars) showing microscopic aspects of the São Geraldo Granite. A) K-feldspar crystal with inclusions of quartz, plagioclase, and muscovite; B) Zoned plagioclase within recrystallized matrix; C) Plagioclase with deformed twinning; D) Quartz recrystallized by grain boundary migration; E) Muscovite grain; F); Muscovite and biotite crystals; G) Garnet crystal with inclusions of quartz; H) Biotite crystal with monazite inclusions. Abbreviations: $B t=$ biotite; $M s=$ muscovite; $M z=$ monazite; $Q t=$ quartz; $K f=K$-feldspar $G t=$ garnet. 

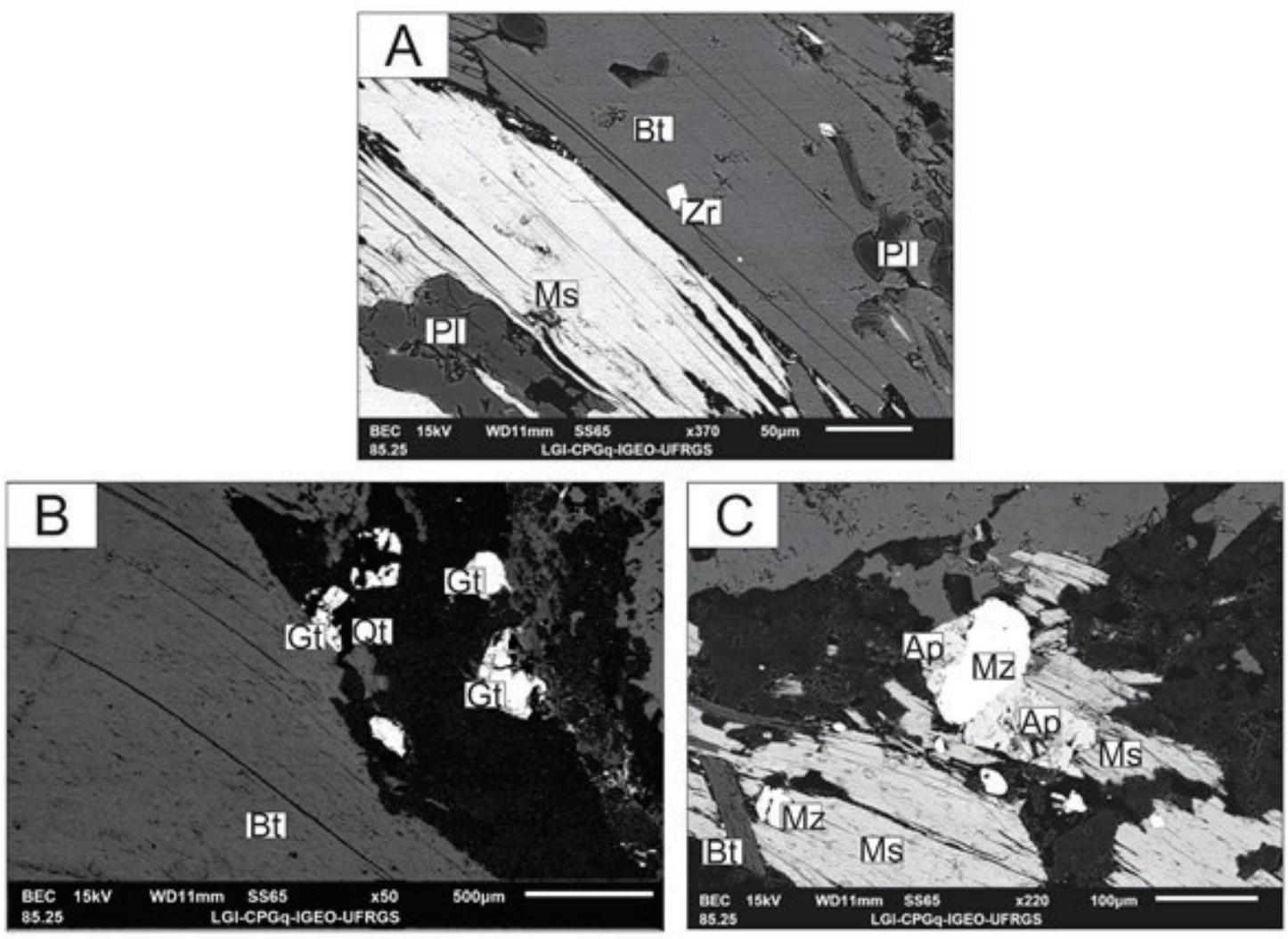

Figura 7. Imagens de elétrons retroespalhados obtida em microscópio eletrônico de varredura. A) Contato entre biotita e muscovita; B) Cristais de granada com inclusões de quartzo; C) Formação de cristais de apatita a partir de cristais de monazita. Abreviações: $\mathrm{Ap}=$ apatita; $\mathrm{Bt}=$ biotita; $\mathrm{Ms}=$ muscovita; $\mathrm{Mz}=$ monazita; $\mathrm{Kf}=\mathrm{K}$-feldspato e $\mathrm{Gt}=$ granada.

Figure 7. Backscattered electron images. A) Contact between muscovite and biotite; B) Garnet crystals with inclusions of quartz; C) Growth of apatite from monazite crystals. Abbreviations: $A p=$ apatite; $B t=$ biotite; $M s=$ muscovite; $M z=$ monazite; $K f=K$-feldspar e $G t=$ garnet.

fluorapatitas são comuns à maioria das rochas magmáticas (e.g. Piccoli \& Candela, 2002).

\section{Discussão dos resultados}

\subsection{Petrogênese do Granito São Geraldo}

Para o granito estudado, a mineralogia constituída por ortoclásio, plagioclásio, quartzo, muscovita e/ou biotita e minerais acessórios como granada, monazita e apatita é compatível com a dos granitos peraluminosos do tipo MPG (muscovite-bearing peraluminous granitoids) de Barbarin (1996, 1999). A presença de muscovita primária, como verificado na petrografia e na química mineral, fortalece a correlação com granitoides peraluminosos do tipo MPG. Granitos desse tipo são os primeiros a serem descritos na região de Porto Alegre.

A textura protomilonítica observada indica que o Granito São Geraldo foi submetido a condições de temperatura e pressão onde prevalece a deformação dúctil (Passchier \& Trouw, 2005). Feições observadas nos cristais de quartzo como recristalização por bulging ocorrem no intervalo de temperaturas entre 250 - $300^{\circ} \mathrm{C}$ (Rosenberg \& Stünitz, 2003) enquanto a presença de cristais de quartzo com subgrãos com extinção do tipo tabuleiro xadrez indica temperaturas de aproximadamente $650^{\circ} \mathrm{C}$ (Khrul, 1996; Passchier \& Trouw, 2005). A presença de subgrãos nas bordas dos cristais de feldspato e recristalização por rotação de subgrão são feições deformacionais que requerem temperaturas elevadas na ordem de $550^{\circ} \mathrm{C}$, pois esses minerais possuem uma grande célula unitária e baixo coeficiente de difusão (Tullis \& Yund, 1991).

A formação de cristais de apatita a partir de cristais de monazita sugere que esse mineral aproveitou os tetraedros de $\mathrm{PO}_{4}$ liberados pela abertura da monazita favorecendo o crescimento da apatita nas bordas dos cristais de monazita. Os estudos de Finger et al. (1998) descrevem que essa reação de substituição começa 
Tabela 1. Composição química e proporções catiônicas $(0=24)$ - Biotita de amostras representativas. ISA = Índice de Saturação em Alumina.

Table 1. Chemistry composition and cationic proportions $(O=24)-$ Biotite from representative samples. ISA = Aluminum Saturation Index.

\begin{tabular}{|c|c|c|c|c|c|c|c|c|c|c|c|c|}
\hline PP & & & SMS & & & & & & & SM43 & & \\
\hline $\mathrm{SiO}_{2}$ & 33,74 & 33,76 & 34,65 & 32,57 & 34,74 & 34,99 & 35,09 & 34,97 & 36,85 & 33,79 & 34,21 & 36,72 \\
\hline $\mathrm{TiO}_{2}$ & 2,69 & 3,34 & 2,63 & 3,01 & 2,65 & 2,97 & 2,81 & 3,00 & 2,07 & 3,70 & 2,29 & 2,50 \\
\hline $\mathrm{Al}_{2} \mathrm{O}_{3}$ & 18,05 & 18,85 & 18,44 & 17,18 & 18,75 & 18,68 & 18,49 & 18,67 & 21,73 & 19,02 & 19,73 & 19,93 \\
\hline $\mathrm{FeO}$ & 25,09 & 23,70 & 24,11 & 22,10 & 24,88 & 23,35 & 24,60 & 24,26 & 21,37 & 24,11 & 24,64 & 19,94 \\
\hline $\mathrm{MnO}$ & 0,29 & 0,34 & 0,26 & 0,26 & 0,36 & 0,26 & 0,48 & 0,49 & 0,32 & 0,47 & 0,50 & 0,37 \\
\hline $\mathrm{MgO}$ & 4,96 & 4,15 & 4,73 & 4,18 & 4,57 & 4,59 & 4,07 & 3,93 & 3,40 & 3,61 & 3,86 & 3,65 \\
\hline $\mathrm{CaO}$ & 0,24 & 0,04 & 0,00 & 0,24 & 0,00 & 0,02 & 0,00 & 0,00 & 0,05 & 0,01 & 0,00 & 0,05 \\
\hline $\mathrm{Na}_{2} \mathrm{O}$ & 0,05 & 0,09 & 0,09 & 8,37 & 0,07 & 0,06 & 0,10 & 0,09 & 0,07 & 0,12 & 0,06 & 0,05 \\
\hline $\mathrm{K}_{2} \mathrm{O}$ & 8,61 & 9,19 & 9,43 & 8,37 & 9,43 & 9,47 & 9,64 & 9,44 & 7,82 & 9,46 & 9,40 & 8,12 \\
\hline $\mathrm{Li}_{2} \mathrm{O}$ & 0,13 & 0,14 & 0,39 & 0,00 & 0,42 & 0,49 & 0,52 & 0,49 & 1,02 & 0,15 & 0,27 & 0,99 \\
\hline $\mathrm{H}_{2} \mathrm{O}$ & 3,76 & 3,77 & 3,82 & 3,78 & 3,86 & 3,85 & 3,85 & 3,85 & 3,97 & 3,79 & 3,82 & 3,87 \\
\hline Total & 97,63 & 97,37 & 98,56 & 100,05 & 99,73 & 98,72 & 99,65 & 99,19 & 98,68 & 98,23 & 98,78 & $96,1 \varepsilon$ \\
\hline $\mathrm{Si}$ & 5,37 & 5,36 & 5,44 & 5,17 & 5,40 & 5,45 & 5,46 & 5,45 & 5,57 & 5,34 & 5,37 & 5,68 \\
\hline $\mathrm{Al}^{\mathrm{iv}}$ & 2,63 & 2,64 & 2,56 & 2,83 & 2,60 & 2,55 & 2,54 & 2,55 & 2,43 & 2,66 & 2,63 & 2,32 \\
\hline $\mathrm{Al}^{\mathrm{vi}}$ & 0,76 & 0,90 & 0,85 & 0,38 & 0,84 & 0,88 & 0,85 & 0,88 & 1,44 & 0,89 & 1,02 & 1,32 \\
\hline $\mathrm{Ti}$ & 0,32 & 0,40 & 0,31 & 0,36 & 0,31 & 0,35 & 0,33 & 0,35 & 0,24 & 0,44 & 0,27 & $0,2 S$ \\
\hline $\mathrm{Fe}$ & 3,34 & 3,15 & 3,16 & 2,93 & 3,24 & 3,04 & 3,20 & 3,16 & 2,70 & 3,19 & 3,24 & 2,58 \\
\hline $\mathrm{Mn}$ & 0,04 & 0,05 & 0,04 & 0,03 & 0,05 & 0,03 & 0,06 & 0,07 & 0,04 & 0,06 & 0,07 & 0,05 \\
\hline $\mathrm{Mg}$ & 1,18 & 0,98 & 1,11 & 0,99 & 1,06 & 1,07 & 0,94 & 0,91 & 0,77 & 0,85 & 0,90 & 0,8 \\
\hline $\mathrm{Li}$ & 0,08 & 0,09 & 0,25 & 0,00 & 0,26 & 0,31 & 0,32 & 0,30 & 0,62 & 0,09 & 0,17 & 0,61 \\
\hline $\mathrm{Ca}$ & 0,04 & 0,01 & 0,00 & 0,04 & 0,00 & 0,00 & 0,00 & 0,00 & 0,01 & 0,00 & 0,00 & 0,01 \\
\hline $\mathrm{Na}$ & 0,02 & 0,03 & 0,03 & 2,57 & 0,02 & 0,02 & 0,03 & 0,03 & 0,02 & 0,04 & 0,02 & 0,02 \\
\hline K & 1,75 & 1,86 & 1,89 & 1,69 & 1,87 & 1,88 & 1,91 & 1,88 & 1,51 & 1,91 & 1,88 & 1,60 \\
\hline $\mathrm{OH}$ & 4,00 & 4,00 & 4,00 & 4,00 & 4,00 & 4,00 & 4,00 & 4,00 & 4,00 & 4,00 & 4,00 & 4,00 \\
\hline TOTAL & 19,54 & 19,46 & 19,63 & 21,00 & 19,65 & 19,59 & 19,65 & 19,59 & 19,34 & 19,46 & 19,57 & 19,32 \\
\hline$Y$ total & 5,73 & 5,56 & 5,71 & 4,69 & 5,76 & 5,68 & 5,71 & 5,68 & 5,80 & 5,52 & 5,67 & 5,70 \\
\hline$X$ total & 1,81 & 1,90 & 1,92 & 4,31 & 1,89 & 1,90 & 1,94 & 1,91 & 1,54 & 1,94 & 1,90 & 1,63 \\
\hline Al total & 3,39 & 3,53 & 3,41 & 3,21 & 3,44 & 3,43 & 3,39 & 3,43 & 3,87 & 3,54 & 3,65 & 3,6 \\
\hline $\mathrm{Fe} / \mathrm{Fe}+\mathrm{Mg}$ & 0,74 & 0,76 & 0,74 & 0,75 & 0,75 & 0,74 & 0,77 & 0,78 & 0,78 & 0,79 & 0,78 & 0,75 \\
\hline ISA & 2,02 & 2,02 & 1,94 & 1,01 & 1,97 & 1,96 & 1,90 & 1,96 & 2,74 & 1,98 & 2,09 & 2,42 \\
\hline
\end{tabular}

com a abertura da monazita a temperaturas aproximadas de $650^{\circ} \mathrm{C}$, compatíveis com as temperaturas de formação das microestruturas observadas no Granito São Gerado.

As análises microestruturais sugerem uma cristalização concomitante à deformação, sob condições de temperatura decrescente atuante durante o seu posicionamento, sugerindo assim uma gênese sintectônica às zonas de cisalhamento que ocorrem na região. Dentre essas, a principal é a Zona de Cisalhamento Porto Alegre, com direção preferencial N45E, relacionada a gênese e alojamento do granito sintrascorrente Lomba do Sabão (Menegat et al., 1998).
A composição peraluminosa do Granito São Geraldo é atestada pela mineralogia semelhante a dos clássicos granitos com duas micas descritos na literatura (Barbarin, 1996, 1999; Chappell \& White, 2001) e também pela composição química que esses minerais apresentam. As biotitas do Granito São Geraldo mostram, no geral, composição semelhante às biotitas de caráter peraluminoso (e.g. AbdelRahman, 1994). Apreciáveis quantidades de Al em coordenação octaédrica são comumente observadas em cristais de biotita de granitos peraluminosos, devido à sua coexistência com muscovita e outros minerais ricos em alumínio. Os altos valores $(1,74-2,74)$ do índice de 


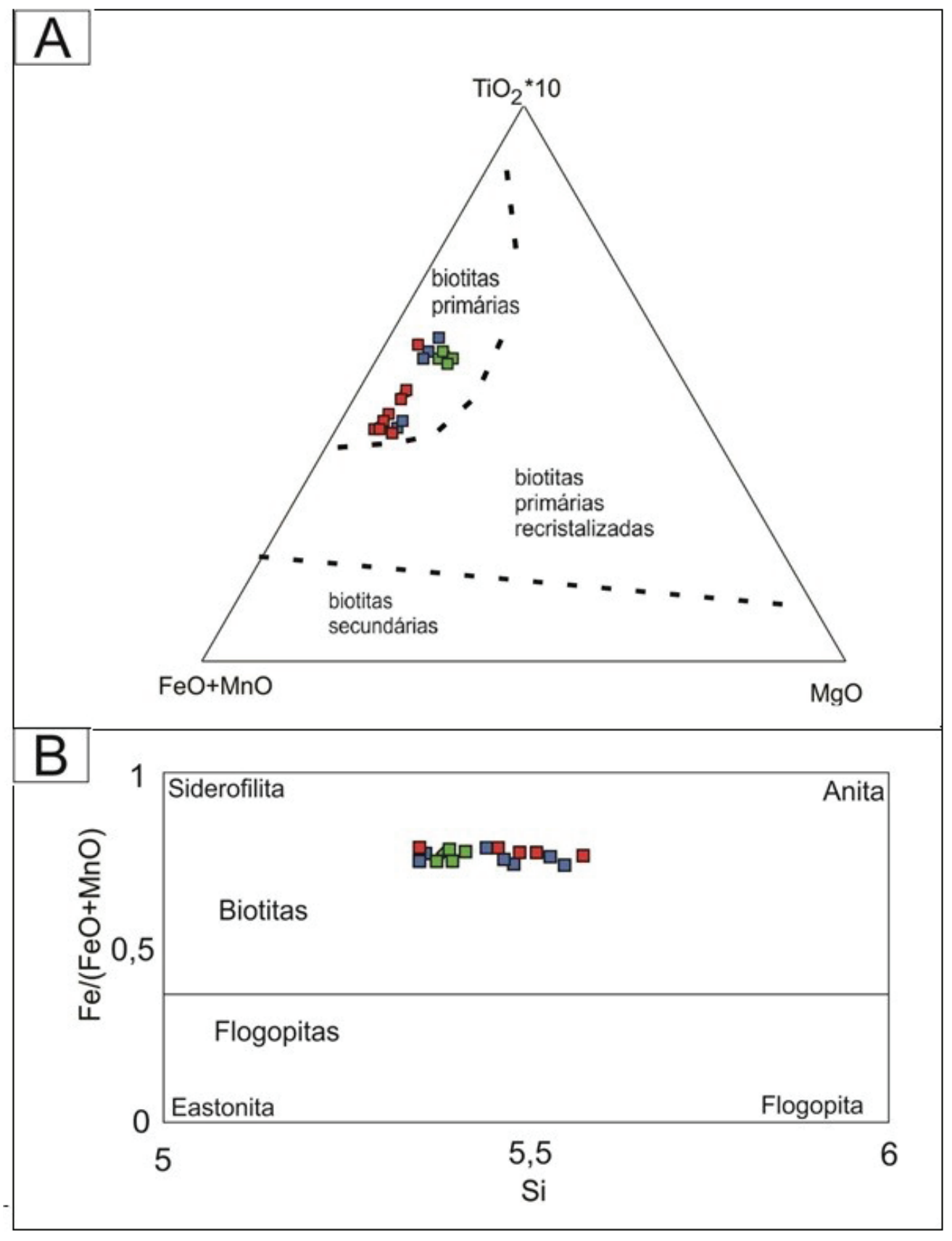

Figura 8. Diagramas químicos para a classificação de biotitas. A) Diagrama ternário $\mathrm{MgO}-\mathrm{TiO}^{2} * 10-\mathrm{MnO}+\mathrm{FeO}$ (modificado de Nachit et al., 1985 ); B) Diagrama Fe / (Fe + Mn) x Si (molar) (modificado de Speer, 1984). Simbologia: quadrados vermelhos = amostra SM9; quadrados azuis = amostra SM43; quadrados verdes = amostras dos Metagranitos Cordilheira e Arroio Francisquinho compiladas de Koester et al. (2001b).

Figure 8. Discrimination diagrams for classification of biotites. A) $\mathrm{MgO}-\mathrm{TiO}^{2} * 10-\mathrm{MnO}+\mathrm{FeO}$ ternary diagram (modified from Nachit et al., 1985); B) Fe / (Fe + Mn) x Si (molar) diagram (modified from Speer, 1984). Symbology: red squares = sample SM9; blue squares = sample SM43; green squares = samples of the Cordilheira and Arroio Francisquinho Metagranites from Koester et al. (2001b). 

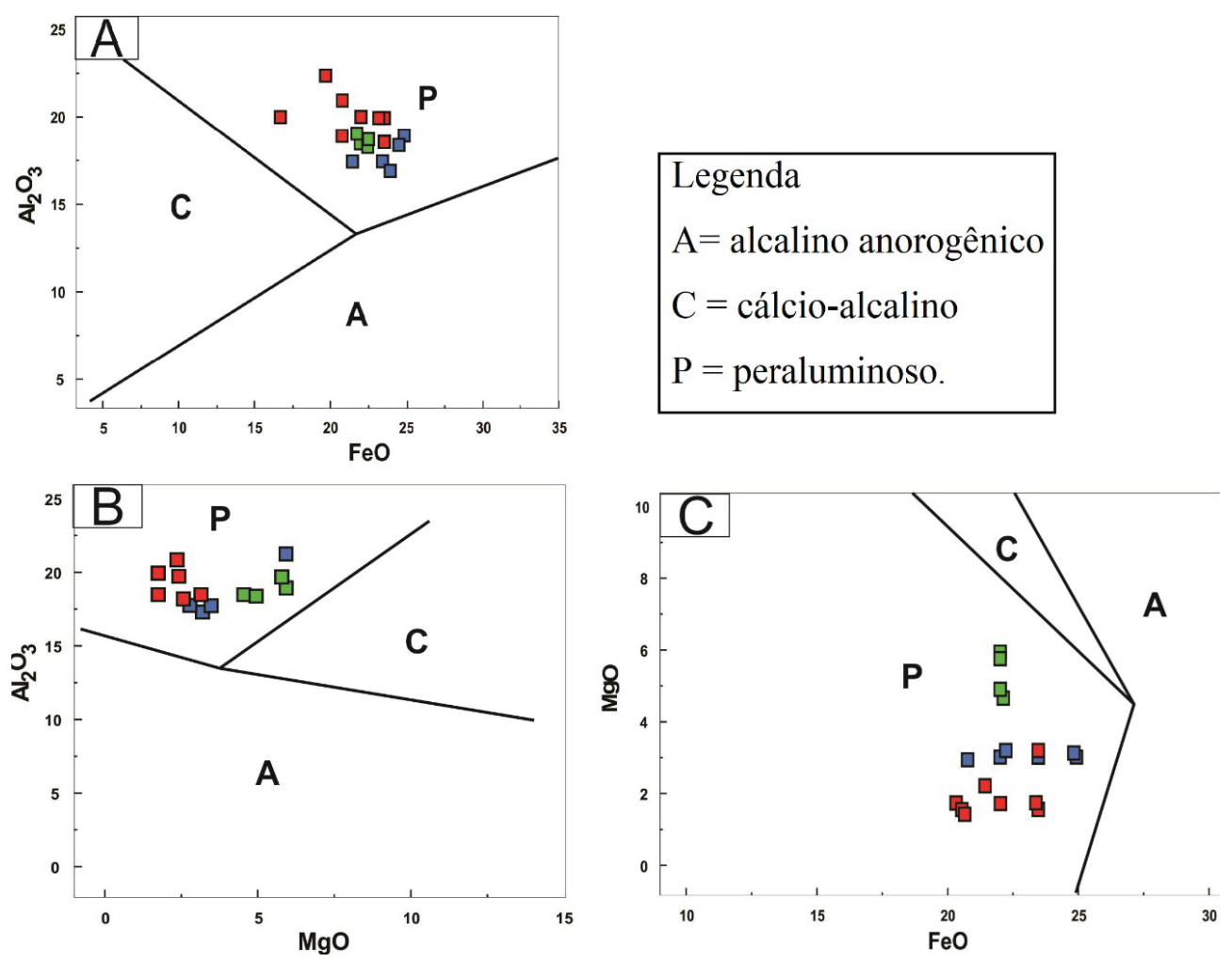

Figura 9. Diagramas discriminantes de séries magmáticas com base na química da biotita de Abdel-Rahman (1994). A) $\mathrm{FeO}$ vs. $\mathrm{Al}^{2} \mathrm{O}^{3}$; $\left.\mathrm{B}\right) \mathrm{MgO}$ vs. $\mathrm{Al}^{2} \mathrm{O}^{3}$; C) $\mathrm{MgO}$ vs. FeO. Símbolos como na figura 8.

Figure 9. Discrimination magmatic series diagrams based on the biotite chemistry (modified from Abdel-Rahman, 1994). A) $\mathrm{FeO}$ vs. $\mathrm{Al}^{2} \mathrm{O}^{3}$; $\left.\mathrm{B}\right) \mathrm{MgO}$ vs. $\mathrm{Al}^{2} \mathrm{O}^{3}$; C) $\mathrm{MgO}$ vs. FeO. Symbols as in figure 8.

Tabela 2. Composição química e proporções catiônicas $(0=22)$ - Muscovitas de amostras representativas. ISA = Índice de Saturação de Alumina.

Table 2. Chemistry composition and cationic proportions $(O=22)-$ Muscovite from representative samples. ISA = Aluminum Saturation Index.

\begin{tabular}{|c|c|c|c|c|c|c|c|c|c|c|c|c|c|}
\hline \multirow{2}{*}{$\frac{\mathrm{PP}}{\mathrm{SiO}_{2}}$} & \multicolumn{6}{|c|}{ SM9 } & \multicolumn{7}{|c|}{ SM43 } \\
\hline & 45,91 & 46,65 & 44,7 & 44,63 & 46,23 & 45,56 & 45,25 & 46,26 & 46,52 & 46,9 & 47,34 & 45,8 & 46,07 \\
\hline $\mathrm{TiO}_{2}$ & 0,15 & 0,8 & 1 & 0,96 & 1,01 & 1,1 & 0,07 & 0,16 & 0,03 & 0,94 & 0,42 & 0,72 & 0,25 \\
\hline $\mathrm{Al}_{2} \mathrm{O}_{3}$ & 35,59 & 34,54 & 33,5 & 31,62 & 34,18 & 33,67 & 34,89 & 34,88 & 35,31 & 34,2 & 33,37 & 33,68 & 34,6 \\
\hline $\mathrm{FeO}$ & 2,32 & 2,28 & 2,27 & 2,17 & 2,28 & 2,23 & 2,24 & 2,41 & 2,59 & 2,35 & 2,6 & 2,38 & 2,64 \\
\hline $\mathrm{MnO}$ & 0,05 & 0,03 & 0 & 0,01 & 0 & 0,01 & 0,04 & 0,03 & 0,06 & 0,01 & 0,03 & 0,02 & 0,04 \\
\hline $\mathrm{MgO}$ & 0,86 & 0,86 & 0,77 & 0,81 & 0,95 & 0,73 & 0,86 & 1,04 & 0,98 & 0,94 & 0,95 & 0,76 & 0,95 \\
\hline $\mathrm{CaO}$ & 0 & 0,01 & 0 & 0,05 & 0 & 0,01 & 0,04 & 0 & 0 & 0 & 0 & 0 & 0 \\
\hline $\mathrm{Na}_{2} \mathrm{O}$ & 0,104 & 0,27 & 0,39 & 0,38 & 0,51 & 0,48 & 0,35 & 0,41 & 0,37 & 0,35 & 0,34 & 0,41 & 0,44 \\
\hline $\mathrm{K}_{2} \mathrm{O}$ & 10,66 & 10,59 & 10,4 & 9,91 & 10,29 & 10,2 & 10,3 & 10,64 & 10,46 & 9,82 & 10,39 & 10,47 & 10,51 \\
\hline Total & 95,66 & 96,04 & 93 & 90,53 & 95,46 & 93,99 & 94,04 & 95,82 & 96,32 & 95,4 & 95,44 & 94,22 & 95,49 \\
\hline $\mathrm{H}_{2} \mathrm{O}$ & 4,7 & 4,73 & 4,54 & 4,44 & 4,7 & 4,62 & 4,62 & 4,71 & 4,74 & 4,73 & 4,72 & 4,62 & 4,68 \\
\hline $\mathrm{Al}^{\mathrm{IV}}$ & 2,14 & 2,09 & 2,11 & 1,97 & 2,1 & 2,08 & 2,12 & 2,11 & 2,11 & 2,05 & 1,98 & 2,06 & 2,1 \\
\hline $\mathrm{Si}$ & 6,11 & 6,19 & 6,09 & 6,69 & 6,14 & 6,17 & 6,13 & 6,16 & 6,16 & 6,23 & 6,32 & 6,2 & 6,16 \\
\hline $\mathrm{Ti}$ & 0,02 & 0,08 & 0,11 & 0,05 & 0,1 & 0,1 & 0,01 & 0,02 & 0 & 0,09 & 0,04 & 0,07 & 0,03 \\
\hline $\mathrm{Fe}$ & 0,26 & 0,25 & 0,26 & 0,25 & 0,26 & 0,26 & 0,25 & 0,27 & 0,29 & 0,26 & 0,29 & 0,27 & 0,3 \\
\hline $\mathrm{Al}^{\mathrm{VI}}$ & 3,21 & 3,07 & 3,11 & 3,06 & 3,05 & 3,07 & 3,22 & 3,13 & 3,15 & 3,06 & 3,02 & 3,09 & 3,12 \\
\hline $\mathrm{Al}^{\text {total }}$ & 5,35 & 5,16 & 5,21 & 5,03 & 5,14 & 5,16 & 5,34 & 5,24 & 5,27 & 5,11 & 5 & 5,15 & 5,22 \\
\hline & 0,6 & 0,6 & 0,62 & 0,6 & 0,57 & 0,63 & 0,59 & 0,57 & 0,6 & 0,58 & 0,61 & 0,64 & 0,61 \\
\hline ISA & 3,31 & 3,18 & 3,1 & 3,06 & 3,16 & 3,15 & 3,26 & 3,16 & 3,26 & 3,36 & 3,11 & 3,1 & 3,16 \\
\hline
\end{tabular}




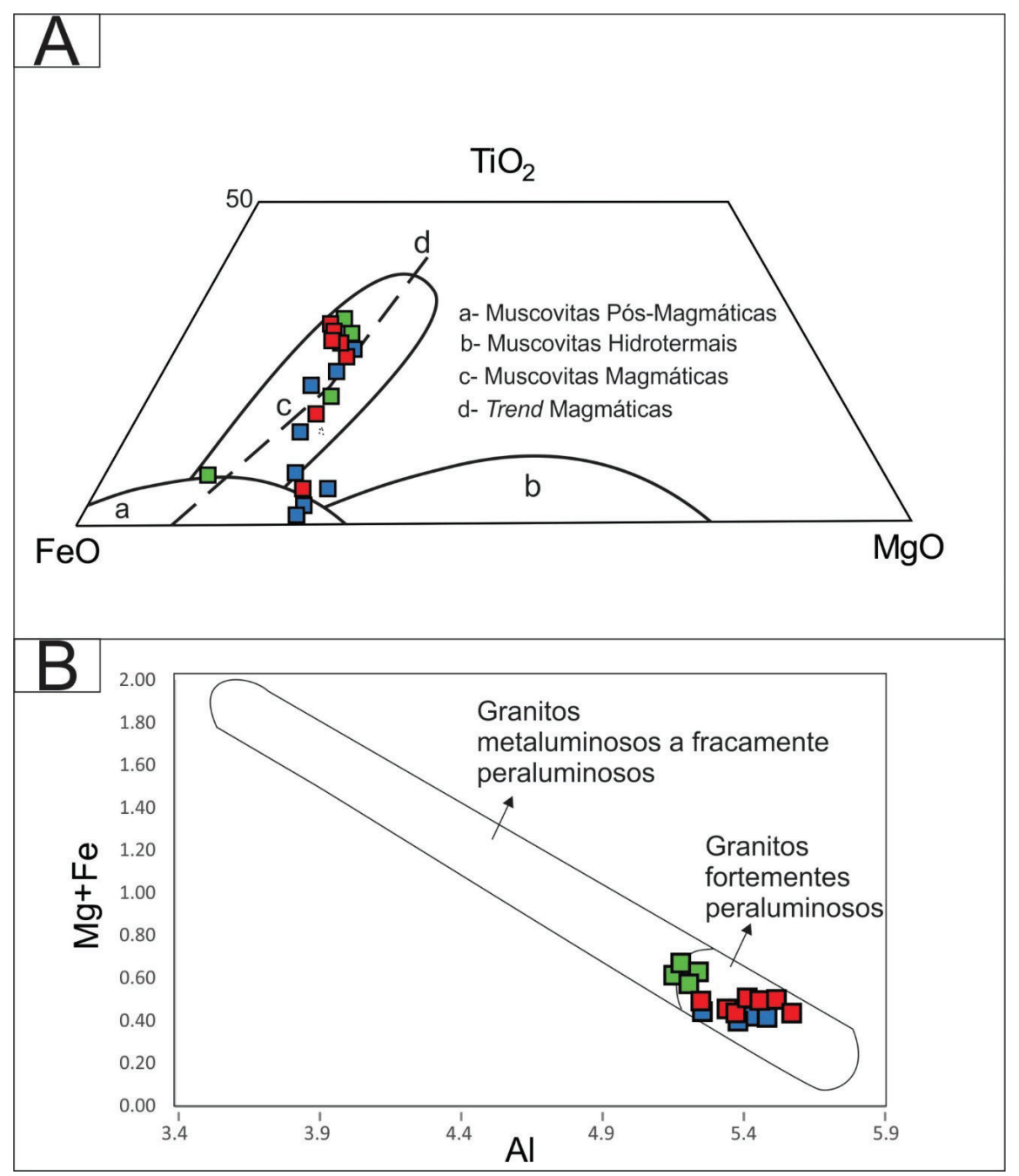

Figura 10. Diagramas de classificação para muscovitas. A) Diagrama ternário $\mathrm{FeO} \times \mathrm{MgO} \times \mathrm{TiO}$, modificado de Speer \& Becker (1992); B) Diagrama Mg + Fe x Al (molar) discriminante entre componentes metaluminosos e fracamente a fortemente peraluminosos (modificado de Zane \& Rizzo, 1999). Símbolos conforme a figura 8.

Figure 10. Muscovite classification diagrams. A) FeO x MgO x TiO2 ternary diagram after Speer \& Becker (1992); B) Mg + Fe x Al (molar) diagram for discrimination of metaluminous and weakly to strongly peraluminous granites (modified from Zane \& Rizzo, 1999). Symbols as in figure 8.

Tabela 3. Composição química e proporções catiônicas $(0=32)$ - K-Feldspatos de amostras representativas. Table 3. Chemical composition and cationic proportions $(\mathrm{O}=32)-K$-Feldspar from representative samples.

\begin{tabular}{l|cc|cc|cc|cc}
\hline \multirow{2}{*}{$\begin{array}{l}\text { Amostra/ } \\
\text { Elemento }\end{array}$} & \multicolumn{3}{|c|}{ K-feldspato SM 9 } & \multicolumn{3}{c}{ K-feldspato SM 43 } \\
\cline { 2 - 9 } $\mathrm{Na}_{2} \mathrm{O}$ & 0,70 & 0,60 & 1,11 & 0,26 & 1,26 & 1,12 & 1,32 & 1,23 \\
$\mathrm{SiO}_{2}$ & 64,34 & 64,07 & 64,21 & 64,27 & 64,52 & 63,52 & 63,97 & 63,32 \\
$\mathrm{MgO}$ & 0,01 & 0,00 & 0,00 & 0,01 & 0,00 & 0,00 & 0,00 & 0,01 \\
$\mathrm{Al}_{2} \mathrm{O}_{3}$ & 18,25 & 18,41 & 18,37 & 18,19 & 18,99 & 18,40 & 18,52 & 18,37 \\
$\mathrm{~K}_{2} \mathrm{O}$ & 15,82 & 16,04 & 15,45 & 16,55 & 14,99 & 15,27 & 16,38 & 16,43 \\
$\mathrm{CaO}$ & 0,00 & 0,00 & 0,00 & 0,00 & 0,00 & 0,00 & 0,00 & 0,00 \\
$\mathrm{Cr}_{2} \mathrm{O}_{3}$ & 0,00 & 0,01 & 0,00 & 0,00 & 0,00 & 0,01 & 0,01 & 0,02 \\
$\mathrm{MnO}$ & 0,00 & 0,00 & 0,00 & 0,02 & 0,02 & 0,00 & 0,02 & 0,01 \\
$\mathrm{FeO}$ & 0,02 & 0,00 & 0,04 & 0,20 & 0,01 & 0,13 & 0,00 & 0,00 \\
$\mathrm{TiO}_{2}$ & 0,03 & 0,02 & 0,00 & 0,03 & 0,03 & 0,02 & 0,02 & 0,01 \\
$\mathrm{Total}$ & 99,17 & 99,15 & 99,17 & 99,53 & 99,82 & 99,47 & 99,25 & 99,39 \\
$\mathrm{An}$ & 0,00 & 0,00 & 0,00 & 0,00 & 0,00 & 0,00 & 0,00 & 0,00 \\
$\mathrm{Ab}$ & 9,02 & 9,87 & 2,3 & 2,3 & 11,34 & 10,02 & 2,91 & 2,07 \\
$\mathrm{Or}$ & 90,98 & 90,13 & 97,7 & 97,7 & 88,66 & 89,98 & 97,09 & 97,93 \\
\hline
\end{tabular}


Tabela 4. Composição química e proporções catiônicas $(0=32)$ - Plagioclásio de amostras representativas. Table 4. Chemical composition and cationic proportions $(\mathrm{O}=32)$ - Plagioclase from representative samples.

\begin{tabular}{c|cc|cc|rrrr}
\hline \multirow{2}{*}{ Amostra/ } & \multicolumn{3}{|c|}{ Plagioclásio Sm 9} & \multicolumn{3}{c}{ Plagioclásio Sm 43} \\
\cline { 2 - 9 } Elemento & \multicolumn{2}{|c|}{ bordas } & \multicolumn{2}{c|}{ núcleos } & \multicolumn{2}{c}{ bordas } & \multicolumn{2}{c}{ núcleos } \\
\hline $\mathrm{Na}_{2} \mathrm{O}$ & 10,19 & 10,50 & 9,77 & 9,89 & 11,15 & 11,39 & 9,89 & 9,88 \\
$\mathrm{SiO}_{2}$ & 65,24 & 65,62 & 64,36 & 64,73 & 66,71 & 67,02 & 64,66 & 64,07 \\
$\mathrm{MgO}$ & 0,00 & 0,00 & 0,00 & 0,01 & 0,01 & 0,01 & 0,01 & 0,00 \\
$\mathrm{Al}_{2} \mathrm{O}_{3}$ & 21,72 & 21,79 & 22,43 & 21,99 & 20,78 & 20,84 & 22,32 & 22,39 \\
$\mathrm{~K}_{2} \mathrm{O}$ & 0,15 & 0,18 & 0,15 & 0,11 & 0,14 & 0,11 & 0,17 & 0,21 \\
$\mathrm{CaO}$ & 2,69 & 2,45 & 3,24 & 2,98 & 1,41 & 1,11 & 3,20 & 3,31 \\
$\mathrm{Cr}_{2} \mathrm{O}_{3}$ & 0,01 & 0,01 & 0,00 & 0,01 & 0,00 & 0,00 & 0,01 & 0,00 \\
$\mathrm{MnO}$ & 0,00 & 0,00 & 0,00 & 0,00 & 0,00 & 0,00 & 0,02 & 0,00 \\
$\mathrm{FeO}$ & 0,00 & 0,03 & 0,00 & 0,02 & 0,04 & 0,00 & 0,06 & 0,07 \\
$\mathrm{TiO} O_{2}$ & 0,03 & 0,00 & 0,01 & 0,01 & 0,01 & 0,00 & 0,00 & 0,03 \\
$\mathrm{Total}$ & 100,04 & 100,59 & 99,97 & 99,75 & 100,27 & 100,49 & 100,34 & 99,95 \\
$\mathrm{An}$ & 16,85 & 11,33 & 15,33 & 10,44 & 6,50 & 5,10 & 15,03 & 15,44 \\
$\mathrm{Ab}$ & 82,62 & 87,66 & 83,79 & 88,09 & 92,71 & 94,32 & 84,01 & 83,42 \\
$\mathrm{Or}$ & 0,52 & 1,01 & 0,87 & 1,47 & 0,79 & 0,58 & 0,97 & 1,14 \\
\hline
\end{tabular}

Tabela 5. Composição química e proporções catiônicas $(O=24)$ - Granadas de amostras representativas. Table 5. Chemical composition and cationic proportions $(\mathrm{O}=24)$ - Garnet from representative samples.

\begin{tabular}{l|rr|rr}
\hline Amostra/ & \multicolumn{2}{|c}{$\mathrm{S} 9$} & \multicolumn{2}{|c}{$\mathrm{SM} 43$} \\
Elemento & \multicolumn{2}{|c}{$\mathrm{SM}$} \\
\hline $\mathrm{SiO}_{2}$ & 37,18 & 35,20 & 36,16 & 34,18 \\
$\mathrm{TiO}_{2}$ & 0,08 & 0,07 & 0,06 & 0,07 \\
$\mathrm{Al}_{2} \mathrm{O}_{3}$ & 21,38 & 22,38 & 20,54 & 22,54 \\
$\mathrm{FeO}$ & 25,49 & 28,13 & 29,22 & 31,07 \\
$\mathrm{MnO}$ & 12,93 & 12,93 & 12,10 & 11,20 \\
$\mathrm{MgO}$ & 0,00 & 0,00 & 0,00 & 0,00 \\
$\mathrm{CaO}$ & 1,00 & 0,94 & 0,81 & 0,72 \\
$\mathrm{TOTAL}$ & 98,06 & 99,65 & 98,89 & 99,79 \\
$\mathrm{Si}$ & 6,13 & 5,80 & 6,02 & 5,68 \\
$\mathrm{Ti}$ & 0,01 & 0,01 & 0,01 & 0,01 \\
$\mathrm{Al}$ & 4,15 & 4,35 & 4,03 & 4,41 \\
$\mathrm{Fe}$ & 3,51 & 3,88 & 4,06 & 4,31 \\
$\mathrm{Mn}$ & 1,80 & 1,81 & 1,70 & 1,57 \\
$\mathrm{Mg}$ & 0,00 & 0,00 & 0,00 & 0,00 \\
$\mathrm{Ca}$ & 0,18 & 0,17 & 0,14 & 0,13 \\
$\mathrm{TOTAL}$ & 15,79 & 16,01 & 15,96 & 16,11 \\
$\mathrm{Py}$ & 0,00 & 0,00 & 0,00 & 0,00 \\
$\mathrm{Alm}$ & 63,94 & 66,30 & 68,73 & 71,70 \\
$\mathrm{Gro}$ & 3,21 & 2,84 & 2,44 & 2,13 \\
$\mathrm{Sp}$ & 32,85 & 30,86 & 28,83 & 26,18 \\
\hline
\end{tabular}


Tabela 6. Composição química e proporções catiônicas $(0=25)$ - Apatita de amostras representativas. Table 6. Chemical composition and cationic proportions $(O=25)$ - Apatite from representative samples.

\begin{tabular}{|c|c|c|c|c|}
\hline $\begin{array}{l}\text { Amostra/ } \\
\text { Elemento }\end{array}$ & \multicolumn{2}{|c|}{ Sm9 } & \multicolumn{2}{|c|}{ Sm43 } \\
\hline $\mathrm{CaO}$ & 56,70 & 55,71 & 53,71 & 54,68 \\
\hline $\mathrm{Na}_{2} \mathrm{O}$ & 0,11 & 0,11 & 0,20 & 0,11 \\
\hline $\mathrm{MnO}$ & 0,20 & 0,31 & 0,20 & 0,20 \\
\hline $\mathrm{FeO}$ & 0,24 & 0,30 & 0,24 & 0,24 \\
\hline $\mathrm{P}_{2} \mathrm{O}_{5}$ & 36,68 & 34,85 & 36,48 & 36,28 \\
\hline $\mathrm{SiO}_{2}$ & 0,29 & 0,30 & 0,29 & 0,29 \\
\hline $\mathrm{Cl}$ & 0,00 & 0,00 & 0,00 & 0,00 \\
\hline $\mathrm{F}$ & 3,04 & 4,38 & 4,50 & 3,40 \\
\hline Total & 97,25 & 95,96 & 95,62 & 95,19 \\
\hline $\mathrm{O}=\mathrm{F}, \mathrm{Cl}$ & 1,28 & 1,84 & 1,89 & 1,43 \\
\hline Total & 95,97 & 94,11 & 93,72 & 93,76 \\
\hline $\mathrm{Ca}$ & 10,44 & 10,51 & 10,05 & 10,29 \\
\hline $\mathrm{Na}$ & 0,04 & 0,04 & 0,07 & 0,04 \\
\hline $\mathrm{Mn}$ & 0,03 & 0,03 & 0,03 & 0,03 \\
\hline $\mathrm{Fe}$ & 0,03 & 0,03 & 0,03 & 0,03 \\
\hline $\mathrm{La}$ & 0,02 & 0,03 & 0,03 & 0,03 \\
\hline $\mathrm{Ce}$ & 0,02 & 0,02 & 0,02 & 0,02 \\
\hline $\mathrm{Nd}$ & 0,02 & 0,02 & 0,02 & 0,02 \\
\hline $\mathrm{P}$ & 5,38 & 5,19 & 5,39 & 5,39 \\
\hline $\mathrm{Si}$ & 0,05 & 0,05 & 0,05 & 0,05 \\
\hline $\mathrm{F}$ & 1,66 & 2,44 & 2,32 & 1,89 \\
\hline $\mathrm{OH}$ & 0,34 & $-0,44$ & $-0,32$ & 0,11 \\
\hline Total & 18,04 & 17,92 & 17,70 & 17,90 \\
\hline
\end{tabular}

saturação em alumina [ISA=Al/ $(\mathrm{Ca}+\mathrm{Na}+\mathrm{K})]$ nos cristais de biotita do Granito São Geraldo são reflexo dessa característica e evidenciam a alta atividade do alumínio no magma que os originou.

Dois tipos de muscovita são distinguidos nas amostras estudadas: cristais euédricos a subédricos bem desenvolvidos, interpretados como primários, e pequenos cristais subédricos de origem secundária (pós-magmáticos) dispersos de forma irregular em feldspatos e biotitas. As análises químicas reforçam essa interpretação, como observado no diagrama ternário Mg-Ti-Na apresentado na figura 10A. As baixas concentrações de $\mathrm{TiO}_{2}$ da muscovita secundária sugerem reequilíbrio subsolidus (Speer \& Becker, 1992).

De acordo com o diagrama proposto por
Zane \& Rizzo (1999) as muscovitas do Granito São Geraldo se distribuem no campo dos granitoides fortemente peraluminosos, semelhantes aos típicos granitoides tipo-S (Chappell \& White, 1992). As características petrográficas e de composição química das muscovitas indicam uma origem primária, formadas a partir de um magma peraluminoso (Miller et al., 1981; Clarke et al., 2005; Dahlquist et al., 2007).

A composição química das apatitas reforça o caráter peraluminoso e tipo-S do Granito São Geraldo. Apatitas com teores elevados de F e baixos de $\mathrm{Cl}$ são comumente descritas em granitos evoluídos, sendo um comportamento que pode ser atribuído à abundância de halogêneos nas rochas-fonte (Piccoli \& Candela, 2002). 


\subsection{Comparação com a Suíte Cordilheira}

Como mencionado anteriormente, 0 Batólito Pelotas, uma das principais associações petrotectônicas do Cinturão Dom Feliciano, é constituído por diversas suítes graníticas. Em uma dessas suítes, a Suíte Cordilheira, a maioria das ocorrências de granitos peraluminosos é agrupada (Philipp et al., 2013). A Suíte Cordilheira é constituída por corpos graníticos alongados, segundo a direção preferencial NE-SW e são correlacionados a partir de suas características de campo, petrográficas, mineralógicas, estruturais, químicas, sendo interpretados como granitoides do tipo MPG e importantes registros de fusão crustal resultantes de processos similares (Fernandes et al., 1995a; Koester, 1995; Nardi \& Frantz, 1995; Philipp, 1998; Koester et al., 2001b, 2001c, 2002; Frantz et al., 2003; Philipp et al., 2013; Klein, 2017; Klein et al., 2018).

Na porção noroeste do Batólito Pelotas as principais ocorrências desses granitoides são os metagranitos Cordilheira e Arroio Francisquinho, sintectônicos à Zona de Cisalhamento Dorsal de Canguçu (Koester et al., 2001b, 2001c), com idades de cristalização de ca. 634 e 625 Ma respectivamente (Frantz et al., 2003). Na porção sul do Batólito Pelotas, destaca-se o Granito Três Figueiras, sintectônico à Zona de Cisalhamento Arroio Grande (Philipp, 1998), com idade de cristalização de ca. 585 Ma (Klein et al., 2018). Estes granitos são essencialmente constituídos por K-feldspato, plagioclásio, quartzo, biotita e muscovita, e possuem tanto suas gêneses quanto seus alojamentos relacionados a zonas de cisalhamento transcorrentes dúcteis (Philipp et al., 2013; Klein et al., 2018). Tendo em vista as características apresentadas neste trabalho para o Granito São Geraldo, é possível correlacionar esse granitoide com os granitos pertencentes a essa suíte, uma vez que este apresenta composição e caráter peraluminoso característico a dos clássicos granitos com duas micas descritos na literatura (Barbarin, 1996, 1999; Chappell \& White, 2001), bem como composição mineralógica similar aos metagranitos Cordilheira e Arroio Francisquinho pertencentes a Suíte Cordilheira, todos com gênese e alojamento relacionados a zonas de cisalhamento transcorrentes.

\section{Conclusões}

O Granito São Geraldo apresenta composição mineralógica essencial constituída por ortoclásio com teores de Or entre 86 a 97 \% que decrescem em direção as bordas dos cristais, oligoclásio que em geral apresentam zonação ígnea normal, quartzo, muscovita (ígnea) e biotita. Como minerais secundários ocorre a presença de muscovitas pós-magmáticas que se desenvolvem sobre os planos de clivagem ou nas bordas das biotitas. Os minerais acessórios são zircão, monazita, almandina, fluorapatita e opacos (ilmenita e magnetita).

As características microestruturais descritas neste estudo sugerem temperaturas entre $650^{\circ} \mathrm{C}$ e $300^{\circ} \mathrm{C}$, onde as microestruturas de mais alta temperatura estariam associadas aos estágios iniciais de cristalização e resfriamento do magma e as de baixa temperatura estariam associadas aos estágios pós-cristalização e resfriamento. Essa diferença de temperatura indica que o alojamento do granito se deu em diferentes estágios de movimentação e calor em um regime transcorrente, possivelmente relacionado com a Zona de Cisalhamento de Porto Alegre.

A composição mineralógica descrita para o granito alvo deste estudo difere de todos os granitoides descritos até então na região de Porto Alegre. Seu caráter peraluminoso sugere semelhança com os granitos com duas micas que compõe a Suíte Cordilheira. Isso é reforçado quando os dados de química mineral do Granito São Geraldo são comparados com os granitos peraluminosos que afloram na região de Encruzilhada do Sul.

A correlação entre os furos de sondagem sugere que o Granito São Geraldo possui uma extensão mínima de 10 km. Apesar de não aflorar em superfície, a presença de um granito peraluminoso sugere um importante evento de fusão crustal na região de Porto Alegre, com possível correlação com os demais eventos de descompressão adiabática seguida de fusões crustais que ocorrem no Cinturão Dom Feliciano e que colaboraram para a formação do Batólito 
Pelotas.

Agradecimentos. Agradecemos aos editores da revista, Paulo A. de Souza e Lauro V.S. Nardi e a revisora do manuscrito Luana Moreira Florisbal. Ao CNPq pelo auxílio e bolsa concedida ao aluno Daniel Triboli Vieira (Processo n 140461/20167).

\section{Referências}

Abdel-Rahman, A.M. 1994. Nature of biotites from alkaline, calc-alkaline, and peraluminous magmas. Journal of Petrology, 35: 525-541.

Barbarin, B. 1996. Genesis of the two main types of peraluminous granitoids. Geology, 24(4): 295-298.

Barbarin, B. 1999. A review of the relationships between granitoid types, their origins and their geodynamic environments. Lithos, 46: 605626.

Bitencourt, M.F. \& Nardi, L.V.S. 2000. Tectonic setting and sources of magmatism related to the Southern Brazilian Shear Belt. Revista Brasileira de Geociências, 30(1): 186-189.

Brown, M. 2013. Granite: From genesis to emplacement. Bulletin of the Geological Society of America 125:1079-1113.

Chappell, B.W. \& White, A.J.R. 1992. I-Type and S-Type granites in the Lachlan Fold Belt. Transaction Royal Society, 83: 1-26.

Chappell, B.W. \& White, A.J.R. 2001. Two contrasting granite types - 25 years later. Australian Journal of Earth Sciences, 48, 489499.

Clarke, D.B, Dorais, M., Barbarin, B., Barker, D., Cesare, B., Clarke, G., el Baghdadi, M., Erdmann, S., Förster, H.J., Gaeta, M., Gottesmann, B., Jamieson, R.A., Kontak, D.J., Koller, F., Gomes, C.L, London, D., Morgan Vi, G.B., Neves, L.J.P.F., Pattison, D.R.M., Pereira, A.J.S.C.,Pichavant, M., Rapela, C.R., Renno, A.D., Richards, S., Roberts, M.,Rottura, A., Saavedra, J., Sial, A.N., Toselli, A.J., Ugidos, J.M., Uher, P., Villaseca, C., Visonà, D.,Whitney, D.L., Williamson, B. \& Woodard, H.H. 2005. Occurrence and origin of andalusite in peraluminous felsic igneous rocks. Journal of Petrology, 46: 441-472.

Costa, A.F.U. 1997. Teste e modelagem geofísica da estruturação das associações litotectônicas pré-cambrianas no Escudo Sul-rio-grandense. Porto Alegre, 291p. Tese de Doutorado, Programa de Pós-Graduação em Geociências, Instituto de Geociências, Universidade Federal do Rio Grande do Sul, Porto Alegre.

Dahlquist, J.A., Galindo, C., Pankhurst, R.J., Rapela, C.W., Alasino, P.H., Saavedra, J. \& Fanning, C.M. 2007. Magmatic evolution of the Peñón Rosado granite: Petrogenesis of garnet-bearing granitoids. Lithos, 95: 177207.

Deer, W.A., Howie, R.A. \& Zussman, J. 1992. An Introduction to the Rock Forming Minerals. Londres, Longman, $2^{\mathrm{a}}$ Ed., 696p.

Fernandes, L.A.D., Tommasi, A. \& Porcher, C.C. 1992. Deformation patterns in the Southern Brazilian Branch of the Pan-African Dom Feliciano Belt. Journal of South American Earth Sciences, 5: 77-96.

Fernandes, L.A.D., Menegat, R., Costa, A.F.U., Koester, E., Kramer, G., Tommasi, A., Porcher, C.C., Ramgrab, G.E. \& Camozzato, E. 1995a. Evolução tectônica do Cinturão Dom Feliciano no Escudo Sul-rio-grandense: Parte I - uma contribuição a partir do registro geológico. Revista Brasileira de Geociências, 25: 351374.

Fernandes, L.A.D., Menegat, R., Costa, A.F.U., Koester, E., Kramer, G., Tommasi, A., Porcher, C.C., Ramgrab, G.E. \& Camozzato, E. 1995b. Evolução tectônica do Cinturão Dom Feliciano no Escudo Sul-rio-grandense: Parte II uma contribuição a partir das assinaturas geofísicas. Revista Brasileira de Geociências, 25: 375-384.

Figueiredo, M.C.H., Fragoso-César, A.R.S. \& Kronberg, B.I. 1990. Litogeoquímica das principais unidades do Batólito Pelotas no Rio Grande do Sul. In: CONGRESSO BRASILEIRO DE GEOLOGIA, 36, 1990, Natal. Anais... Natal, SBG, v. 4, p. 1723-1738.

Finger, F., Broska, I., Roberts, M.P. \& Schermaier, A. 1998. Replacement of primary monazite by apatite - allanite - epidote coronas in an amphibolite facies granite gneiss from the eastern Alps. American Mineralogist, 83: 248258. 
Fragoso-Cesar, A.R.S., Figueiredo, M.C.H., Soliani Jr., E. \& Faccini, U.F. 1986. O Batólito Pelotas (Proterozóico Superior/Eo-Paleozóico) no Escudo do Rio Grande do Sul. In: CONGRESSO BRASILEIRO DE GEOLOGIA, 34, 1986, Goiânia. Anais... Goiânia, SBG, v. 3, p. 13-22.

Frantz, J.C., McNaughton, N.J., Marques, J.C., Hartmann, L.A., Botelho, N.F. \& Caravaca, G. 2003. SHRIMP U-Pb zircon ages of granitoids from southernmost Brazil: constrains on the temporal evolution of the Dorsal de Canguçu transcurrent Shear Zone and Eastern Dom Feliciano Belt. In: South American Symposium on Isotope Geology, 4, 2003, Salvador. Short Papers, v. 1, p. 174-177.

Gill, R. 2010. Igneous rocks and processes: a practical guide. Oxford, Wiley-Blackwell, 390p.

Gomes, V.F. 2016. Petrografia e Geoquímica dos Gnaisses Chácara das Pedras, Nordeste do Cinturão Dom Feliciano. Pelotas, 68p. Trabalho de conclusão de curso em Engenharia Geológica, Centro das Engenharias da Universidade Federal de Pelotas.

Gregory, T.R., M.F., Bitencourt, Nardi, L. V., Florisbal, L. M, Chemale, F. Jr. 2015. Geochronological data from TTG-type rock associations of the Arroio dos Ratos Complex and implications for crustal evolution of southernmost Brazil in Paleoproterozoic times. Journal of South American Earth Sciences, 57, 49-60.

Heilbron, M., Pedrosa-Soares, A.C., Campos Neto, M., Silva, L.C. \& Trouw, R.A.J. 2004. A Província Mantiqueira. In: Mantesso Neto, A., Bartorelli, A., Carneiro, C.D.R. \& Brito Neves, B.B. (Eds.). O desvendar de um continente: a moderna geologia da América do Sul e o legado da obra de Fernando Flávio Marques de Almeida. São Paulo, Beca, p. 203-234.

Klein, F.G. 2017. Petrologia do Granito Três Figueiras, sudeste do Cinturão Dom Feliciano, RS. Porto Alegre, 74p. Dissertação de Mestrado, Programa de Pós-Graduação em Geociências, Instituto de Geociências, Universidade Federal do Rio Grande do Sul.

Klein, F.G., Koester, E., Vieira, D.T., Porcher, C.C., Ramos, R.C. \& Philipp, R.P. 2018. Geologia do Granito Três Figueiras: magmatismo peraluminoso de $585 \mathrm{Ma}$ no sudeste do Cinturão Dom Feliciano. Pesquisas em
Geociências, 45(2): e665.

Koester, E. 1995. Petrologia e geocronologia dos granitóides sintectônicos à Zona de Cisalhamento Dorsal de Canguçu. Porto Alegre, 240p. Dissertação de Mestrado, Programa de Pós-Graduação em Geociências, Instituto de Geociências, Universidade Federal do Rio Grande do Sul.

Koester, E., Soliani Jr., E., Leite, J.A.D., Hartmann, L.A., Fernandes, L.A.D., McNaughton, N.J., Santos, J.O.S. \& Oliveira, L. D. 2001a. SHRIMP $\mathrm{U}-\mathrm{Pb}$ age for the emplacement of the Santana Granite and reactivation of the Porto Alegre Suture, southern Brazil. Journal of South American Earth Sciences, 14(1): 91-99.

Koester, E., Fernandes, L.A.D., Soliani Jr., E., Kraemer, G., Nardi, L.V.S. \& Roisemberg, A. 2001b. Geologia e geoquímica dos granitóides sintectônicos à Zona de Cisalhamento Transcorrente Dorsal de Canguçu, Encruzilhada do Sul, RS. Revista Brasileira de Geociências, 31 (2): 141-154.

Koester, E., Roisenberg, A., Fernandes, L.A.D., Soliani Jr., E., Nardi, L.V.S. \& Kraemer, G. 2001 c. Petrologia dos granitóides sintectônicos à Zona de Cisalhamento Transcorrente Dorsal de Canguçu, Encruzilhada do Sul, RS. Revista Brasileira de Geociências, 31(2): 131-140.

Koester, E., Porcher, C.C., Pimentel, M.M., Fernandes, L.A.D., Vignol-Lelarge, M.L., Oliveira, L.D. \& Ramos, R.C. 2016. Further evidence of 777 Ma subduction-related continental arc magmatism in Eastern Dom Feliciano Belt, southern Brazil: The Chácara das Pedras Orthogneiss. Journal of South American Earth Sciences, 68: 155-166.

Kruhl, J.H. 1996. Prism- and basisparallel subgrain boundaries in quartz: a microstructural geothermobarometer. Journal of Metamorphic Geology, 14, 581-589.

Lameyre, J. \& Bowden, P. 1982. Plutonic rock types series: discrimination of various granitoid series and related rocks. Journal of Volcanology and Geothermal Research, 14(1/2): 169-186.

Liégeois, J.P, Navez, J., Hertogen, J. \& Black, R. 1998. Contrasting origin of post-collisional high-K calc-alkaline and shoshonitic versus alkaline and peralkaline granitoids. The use of 
sliding normalization. Lithos, 45: 1-28.

Martil, M.M., Bitencourt, M.F., Nardi, L.V.S., Koester, E. \& Pimentel, M.M. 2017. Precollisional, Tonian (ca. $790 \mathrm{Ma}$ ) continental arc magmatism in southern Mantiqueira Province, Brazil: geochemical and isotopic constraints from the Várzea do Capivarita Complex. Lithos, 274/275: 39-52.

Masquelin, H., Fernandes, L.A.D., Lenz, C., Porcher, C.C. \& McNaughton, N.J. 2012. The Cerro Olivo Complex: a pre-collisional Neoproterozoic magmatic arc in Eastern Uruguay. International Geology Review, 54: 1161-1183.

Menegat, R., Fernandes, L.A.D., Koester, E. \& Scherer, C.M.S. 1998. Porto Alegre antes do Homem: evolução geológica. In: Menegat, R., Porto, M.L., Carraro, C.C. \& Fernandes, L.A.D. (Eds.). Atlas Ambiental de Porto Alegre. Porto Alegre, Editora da Universidade Federal do Rio Grande do Sul, p. 11-24.

Miller, C.F., Stoddard, E.F., Bradfish, L.J. \& Dollase, W.A. 1981. Composition of plutonic muscovite. Genetic implications. Canadian Mineralogist, 19: 25-34.

Nachit, H., Razafımahefa, N., Stussi, J.M. \& Carron, J.P. 1985. Composition chimique des biotites et typologie magmatique des granitoides. Comptes Rendus de l'Académie des sciences Paris, 301: 810-818.

Nardi, L.V.S. 2016. Granitoides e séries magmáticas: o estudo contextualizado dos granitoides. Pesquisas em Geociências, 43(1): 85-99.

Nardi, L.V.S. \& Frantz, J.C. 1995. The Cordilheira intrusive suite: late Proterozoic peraluminous granitoids from the southern Brazil. Journal of South American Earth Sciences, 8(1): 55-63.

Nardi, L.V.S. \& Bonin, B. 1991. Post orogenic and non-orogenic alkaline granite associations: the Saibro Intrusive Suite, Southern Brasil: a case study. Chemical Geology, 92: 197-212.

Nardi, L.V.S., Plá Cid, J. \& Bitencourt, M.F. 2007. Geochemistry of mafic microgranular

enclaves and their relationship with the host syenite within the mantle pressure lamprophyresyenite systems (Piquiri Massif) of Southern Brazil. Mineralogy and Petrology, 91: 101-116.

Nardi, L.V.S., Plá Cid, J., Bitencourt, M.F. \& Stabel,
L. 2008. Geochemistry and petrogenesis of post-collisional ultrapotassic syenites and granites from

southernmost Brazil: the Piquiri Syenite Massif. Anais da Academia Brasileira de Ciências, 80(2): 353-371.

Oliveira, L. D., Koester, E. \& Soliani Jr., E. 2001. Geoquímica das rochas graníticas póstranscorrentes da região de Porto Alegre e Viamão, RS. Geochimica Brasiliensis, 15(2): 65-92.

Passchier, C.W. \& Trouw, R.A.J. 2005. Microtectonics. Berlim, Springer Verlag, 366 p. Patiño-Douce, A.E. \& Johnston, A.D. 1991. Phase equilibria and melt productivity in the pelitic system: implications for the origin of peraluminous granitoids and aluminous granulites. Contributions to Mineralogy and Petrology, 107: 202-218.

Patiño-Douce, A.E. \& McCarthy, T.C. 1998. Melting of crustal rocks during continental collision and subduction. In: Hacker, B.R. \& Liou, J.G. (Eds.). When Continents Collide: Geodynamics and Geochemistry of Ultra-high Pressure Rocks. Dordrecht, Kluwer Academic, p. 27-55.

Pérez-Soba, C. \& Villaseca, C. 2010. Petrogenesis of highly fractionated I-type peraluminous granites: La Pedriza pluton (Spanish Central System). Geologica Acta, 8:131-149.

Philipp, R.P. 1990. Geologia e Petroquímica dos granitóides da região de Monte Bonito, Pelotas. RS. Porto Alegre, 231p. Dissertação de Mestrado, Programa de Pós- Graduação em Geociências, Instituto de Geociências, Universidade Federal do Rio Grande do Sul.

Philipp, R.P. 1998. A evolução geológica e tectônica do Batólito Pelotas no Rio Grande do Sul. São Paulo, 255p. Tese de Doutorado, Programa de Pós-Graduação em Geociências, Instituto de Geociências, Universidade de São Paulo.

Philipp, R.P. \& Machado, R. 2001. Ocorrência e significado dos septos do embasamento encontrados nas suítes graníticas do Batólito Pelotas, RS, Brasil. Pesquisas em Geociências, 29(1): 43-57.

Philipp, R.P. \& Campos, R. 2004. Geologia, petrografia e litogeoquímica dos Gnaisses Porto Alegre, RS, Brasil: implicações 
geotectônicas. Pesquisas em Geociências, 31(2): 79-94

Philipp, R.P. \& Machado, R. 2005. The Neoproterozoic to Cambrian Granitic Magmatism of Pelotas Batholith, Southern Brazil. Journal of South American Earth Sciences, 19: 461-478.

Philipp, R.P., Machado, R., Nardi, L.V.S. \& Lafon, J.M. 2002. O magmatismo granítico Neoproterozóico do Batólito Pelotas no sul do Brasil: novos dados e revisão de geocronologia regional. Revista Brasileira de Geociências, 32(2): 277-290.

Philipp, R.P., Massone, H.J \& Campos, R.S. 2013. Peraluminous leucogranites of the Cordilheira Suite: A record of Neoproterozoic collision and the generation of the Pelotas Batholith, Dom Feliciano Belt, Southern Brazil. Journal of South American Earth Sciences, 43: 08-24.

Philipp, R.P., Pimentel, M.M. \& Chemale Jr., F. 2016. Tectonic evolution of the Dom Feliciano Belt in Southern Brazil: geological relationships and $\mathrm{U}-\mathrm{Pb}$ geochronology. Brazilian Journal of Geology, 46(1), 83-104.

Phillips, E.R. 1980. On Polygenetic Myrmekyte. Geological Magazine, 177(1): 29-36.

Plá Cid, J., Nardi, L.V.S., Stabel, L.Z., Conceição, R.V. \& Balzaretti, N.M. 2003. High-pressure minerals in mafic microgranular enclaves: evidences for co-mingling between lamprophyric and syenitic magmas at mantle conditions. Contributions to Mineralogy and Petrology, 145: 444-459.

Plá Cid J., Nardi, L.V.S., Enrique, P., Merlet, C. \& Boyer, B. 2005. SIMS analysis on trace and rare earth elements in coexisting clinopyroxene and mica from minette mafic enclaves in potassic syenites crystallized under high pressures. Contributions to Mineralogy and Petrology, 148: 675-688.

Reichardt, H., Weinberg, R.F., Andersson, U.B. \& Fanning, C.M. 2010. Hybridization of granitic magmas in the source: The origin of the
Karakoram Batholith, Ladakh, NW India. Lithos, 116: 249-272.

Rosenberg, C.L. \& Stünitz, H. 2003. Deformation and recrystallization of plagioclase along temperature gradient: an example from the Bergell tonalite. Journal of Structural Geology, 25: 389-408.

Sawyer, E.W., Cesare, B. \& Brown, M. 2011. When the continental crust melts. Elements, 7: 227232.

Searle, M.P., Metcalfe, R.P., Rex, A.J. \& Norry, M.J. 1993. Field relations, petrogenesis and emplacement of the Bhagirathi leucogranite, Garhwal Himalaya. In: Treloar, P.J. \& Searle, M.P. (Eds). Himalayan Tectonics. Geological Society, London, Special Publications, 74, 429444.

Speer, J.A. 1984. Micas in igneous rocks. In: Bailey, S.W. (Ed.). Micas. Reviews in Mineralogy, 13: 299-356.

Speer, J.A. \& Becker, S.W. 1992. Evolution of magmatic and subsolidus AFM mineral assemblages in granitoid rocks: biotite, muscovite, and garnet in the Cuffytown Creek, pluton, South-Carolina. American Mineralogist, 77: 821-833

Streckeisen, A.L. 1976. Classification of the common igneous rocks by means of their chemical composition: a provisional attempt. Neues Jahrbuch für Mineralogie, 1: 1-15.

Tullis, J. \& Yund, R.A. 1991. Diffusion creep in feldspar aggregates: experimental evidence. Journal of Structural Geology, 13: 987-1000.

White, A.J.R. \& Chappell, B.W. 1974. Ultrametamorphism and granitoid genesis. Tectonophysics, 43: 7-22.

Wilson, M. 1989. Igneous Petrology. Londres, Unwin and Hyman, 466p.

Zane, A. \& Rizzo, G. 1999. The compositional space of muscovite in granitic rocks. Canadian Mineralogist, 37: 1229-1238.

Manuscrito 773 | Recebido em maio de 2018 | Aceito em jul. de 2019 | Editores: Carla E. Barros e Paulo A. Souza 